\title{
CONTRACTUAL SIGNALLING, RELATIONSHIP-SPECIFIC INVESTMENT AND EXCLUSIVE AGREEMENTS*
}

\author{
LUÍS VASCONCELOS ${ }^{\dagger}$
}

\begin{abstract}
I analyze a simple model of hold-up with asymmetric information at the contracting stage. I show that contractual signalling and efficiency of investment can conflict if only quantity is contractible. This is because contracted quantity encourages investment in the relationship but also signals information. This conflict generates inefficient equilibria in terms of investment. Contracting on exclusivity in addition to quantity resolves the conflict (and consequently eliminates the inefficiency of investment) when the asymmetry of information concerns the value of trade with external parties. While exclusivity also signals information, unlike quantity it does not directly affect relationship-specific investment.

Keywords: Relationship-specific investment, asymmetric information, hold-up, exclusivity.

JEL Classification: L14, L40, D82, K21
\end{abstract}

\section{INTRODUCTION}

Many relationships are formed under asymmetric information. When two or more parties meet to agree on the terms of a future relationship, some of them may have relevant private information about how successful the relationship will be. For example, in vertical relationships, a final good producer contracting with a specific supplier about future trade may have private information about her future value of trading with the supplier. Similarly, a manufacturer offering a franchising agreement to a retailer may be better informed than the retailer about the retailer's ability to sell his product. As was emphasized by Myerson (1983) and Maskin and Tirole (1992), in these cases, if the parties with private information participate in the design of the contract (or the terms of the relationship if established in an informal way), the contract's terms may reveal some of their private information to the other parties. Because of this information transmission effect, the design of the contract assumes a strategic role not present when contracting parties have symmetric information. If investment in the

Date: December 2007.

*I especially thank Mike Whinston, for extremely valuable suggestions. I also thank Adeline Delavande, Alessandro Pavan, Allan Collard-Wexler, Asher Wolinsky, Bentley MacLeod, Fabio Braggion, Juan Carrillo, Ran Abramitzky, William Rogerson, and seminar participants at Columbia University, Northwestern University, University of Rochester, Universidade Nova de Lisboa, and University of Southern California. Financial support from the Fundação para a Ciência e Tecnologia and the Northwestern University Center for the Study of Industrial Organization are gratefully acknowledged.

${ }^{\dagger}$ Contact information: L-vasconcelos@fe.unl.pt. Universidade Nova de Lisboa, Faculdade de Economia, Campus de Campolide, 1099-032 Lisboa, Portugal. 
relationship is important, this role is in addition to the efficiency role of providing the parties with the right incentives to invest that is typical to the hold-up problem literature.

In this paper, I consider a simple model of hold-up with asymmetric information at the contracting stage. In the model a principal (e.g., a buyer) with private information wishes to encourage an agent (e.g., a supplier) to make a relationship-specific investment. I analyze how the two roles of contracting mentioned above interact with one another and highlight a pro-efficiency role of exclusivity agreements. I first consider the case of quantity contracts (or, so-called specific-performance contracts, which specify the default number of units the parties will trade) and show that because of information concerns, the principal may distort the contract's terms away from those that generate incentives for efficient investment in the relationship. I then consider the case of contracts that in addition to quantity specify an exclusivity clause that restricts the principal to trade only with the agent, and show that exclusivity plays an important role in eliminating such contractual distortions and thereby the inefficiency of investment. This result rationalizes the use of contracts that specify both quantity and exclusivity. It also rationalizes the use of exclusivity in situations of hold-up with pure relationship-specific investments.

Both the contractual distortions and the effect of contractibility of exclusivity on relationshipspecific investment highlighted here are novel in the literature. This is because the existing literature on the hold-up problem (e.g., Grossman and Hart, 1986; Edlin and Reichelstein, 1996; and Che and Hausch, 1999), and in particular that on the interaction between exclusivity and relationship-specific investment (e.g., Segal and Whinston, 2000; and De Meza and Selvaggi, 2007), has focused on situations where parties' information is symmetric at the initial contracting stage.

The model I consider is a standard model of hold-up, with the exception that at the contracting stage the party who proposes the contract has private information. Specifically, I consider a model in which a principal and an agent first meet and contract about future transactions, while knowing that later on, the principal may wish to trade with an external party instead. Possible contractual agreements include: a contracted quantity, which corresponds to the default quantity that parties will trade; and a contracted level of exclusivity, restricting the principal to trade only with the agent. At the initial contracting stage, both parties are uncertain about the value of the relationship, but the principal has better information about how successful it will be. This is either because she is better informed about how much she values trade with the agent (private internal information) or because she is better informed about the value of her future outside options (private external information). I consider both cases of internal and external information because, as I show, the source of asymmetry of information affects which forms of contractual commitment are effective in signalling information. Once both parties agree on a contract, a relationship is formed and the agent has the opportunity to invest in it. At a latter date, uncertainty is realized and both the principal and the agent observe the value of trading with each other and the value of the principal's trade with others. At this point, the principal and agent renegotiate the 
initial contract whenever it is inefficient. ${ }^{1}$ Although renegotiated, the initial contract still matters because it determines the status quo positions of both parties (disagreement point) during renegotiation.

I find that if the contract can specify quantity but not exclusivity, signalling information by the principal to extract surplus from the agent and efficiency of investment can conflict with one another. This conflict generates inefficient equilibria, as the principal contracts a quantity that distorts the agent's investment decision relative to its socially efficient level to signal information. I also show that when the principal's private information is internal, contractibility of exclusivity does not affect the set of equilibrium outcomes. As a consequence, when the principal has private internal information only, the possibility to use exclusivity in addition to quantity in the contract does not play any role in mitigating the conflict between surplus extraction and investment incentives.

I finally show that in contrast with the case of internal information, when the principal's private information is external, the conflict between signalling information to extract surplus and investment incentives can be resolved if the principal can use both quantity and exclusivity in the contract. This is because, when the principal's private information is about the value of her outside option, exclusivity serves as a strong signal of that information; and because, in contrast to contracted quantity, exclusivity does not affect directly the agent's investment decision. Thus, when both quantity and exclusivity are contractible, the principal can set contracted quantity to induce optimal investment by the agent, and then adjust contracted exclusivity, without affecting the agent's investment decision, in a way that the combination of the signalling effects of contracted quantity and exclusivity allow her to signal information and extract surplus.

The efficiency effect of exclusivity identified here is important for two reasons. First, in contrast to Segal and Whinston (2000), it rationalizes the use of exclusive contracts in situations of hold-up with pure relationship-specific investments. Motivated by informal discussions (in anti-trust and exclusive contracts) on whether exclusive provisions foster relationship-specific investments, Segal and Whinston (2000) show that exclusivity does not affect whatsoever investments that are fully relationship-specific, when information is symmetric at the contracting stage. ${ }^{2}$ Second, it contributes to the unsettled debate on whether exclusive agreements

\footnotetext{
${ }^{1}$ By considering that parties observe valuations of trade and subsequently renegotiate the initial contract, two important features of many relationships are captured. First, parties to a relationship often learn its real value (only) after the relationship has started. Second, in those cases, parties tend to renegotiate initial contracts that are inefficient ex-post. Beaudry and Poitevin (1993) study equilibrium contracting by an informed party in a setting with renegotiation. They consider the case in which the asymmetry of information persists during the renegotiation stage.

${ }^{2}$ In De Meza and Selvaggi (2007), the authors show that exclusivity may affect relationship-specific investments. Their result differs from that in Segal and Whinston (2000) because they consider a different bargaining game. Our effect is totally different from that in De Meza and Selvaggi (2007), as it stems from the existence of asymmetric information at the contracting stage.
} 
should be contractually allowed by courts or not. In this specific matter, a long-standing concern of courts is that exclusive contracts serve anticompetitive purposes, and consequently prevent efficiency.

By studying contractual signalling by an informed party in the presence of relationshipspecific investment, this paper is inherently related to two strands of the literature: the literature on the hold-up problem and the literature on contract design by an informed party. The existing literature on the hold-up problem assumes symmetric information at the initial contracting stage (e.g., Hart and Moore, 1990; Chung, 1991; Rogerson, 1992; MacLeod and Malcomson, 1993; Aghion et al., 1994; and Segal and Whinston, 2000). By studying contract design by an informed party in a relationship with specific investments, this paper extends the literature on the hold-up problem to the case in which there is asymmetric information at the contracting stage. In the hold-up problem literature (with symmetric information at the contracting stage), the contract is typically designed with one goal: to provide the right incentives to invest. The presence of asymmetric information at the contracting stage introduces a new role for the contract: signalling information to extract surplus.

The literature on contract design by an informed principal can be divided into two groups. The first group focuses on the characterization (in a general way) of the equilibrium contract proposal by an informed principal in a principal-agent relationship (e.g., Myerson, 1983; Maskin and Tirole, 1990; Maskin and Tirole, 1992; and Beaudry and Poitevin, 1993). The modelling approach is this paper is in the spirit of that in Maskin and Tirole (1992). In the context of the model in this paper, I extend their analysis and results to the case in which the agent makes a noncontractible investment decision. This extension is not a trivial one. Maskin and Tirole (1992) assume that all payoff relevant variables are contractible. In their model, the agent's beliefs about the principal's type affect only the agent's decision to accept the contracts proposed by the principal. In the model in this paper those beliefs also affect the agent's investment decision, which in turn affects the principal's payoff (and preferences over contracts). So, in here, the agent's beliefs at the end of the contracting phase are still important. The second group of this literature has studied contract design by an informed party in more concrete settings (e.g., Aghion and Bolton, 1987; Aghion and Hermalin, 1990; Spier, 1992; and Nosal, 2006). ${ }^{3}$ The articles in this literature have not studied specifically the relationship between contractual signalling and relationship-specific investment.

The paper is structured as follows. In Section 2, I present the model. In Section 3, I establish the result that exclusivity is irrelevant in terms of equilibrium outcomes when the principal's private information is internal. In Section 4, I analyze equilibrium outcomes when contracts specify only quantity and then when contracts can specify both quantity

\footnotetext{
${ }^{3}$ For example, Aghion and Hermalin (1990) use a contract signalling model to show that imposing legal restrictions on private contracts can enhance efficiency. Spier (1992) identifies a reason for contractual incompleteness by showing that an informed principal can signal information by deliberately proposing an incomplete contract to an agent. Nosal (2006) considers a situation of contract signalling when studying the incentives of a principal to acquire private information before contracting with an agent.
} 


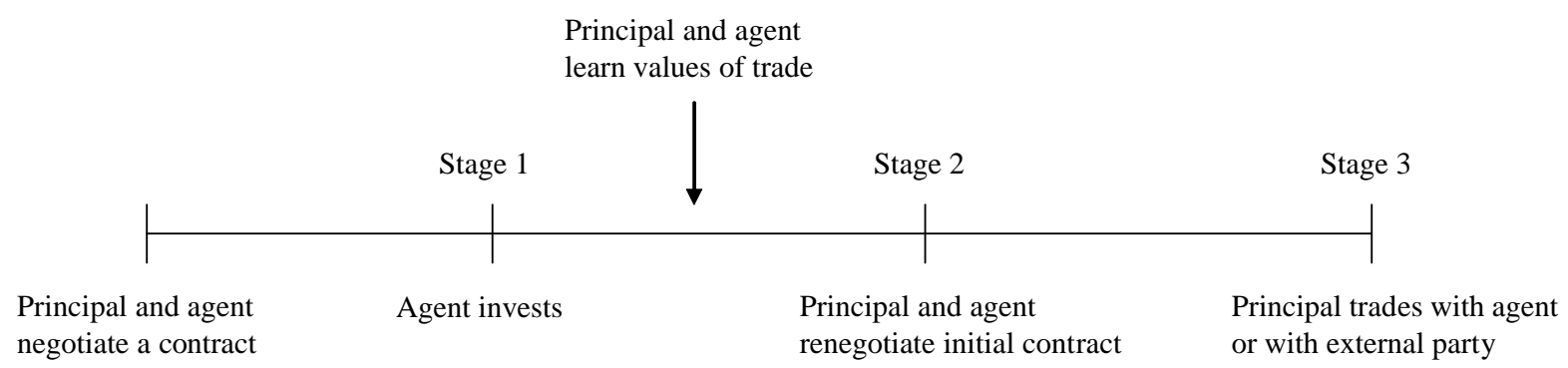

FigURE 1. Sequence of events.

and exclusivity. I show the existence of inefficient equilibria in terms of investment and how exclusivity resolves this inefficiency. In Section 5, I present concluding remarks.

\section{THE Model}

The model delineated in this section and the subsequent analysis are presented in terms of a generic trade relationship between a principal with private information and an agent who can invest in the relationship by preparing for trade. The following are trivial applications of the model: $(i)$ a buyer with private information about how much she values a given product contracting with a supplier about the quantity to be delivered, when the supplier still has to design the product and initiate its production; (ii) a manufacturer with private information about her production cost contracting with a retailer about supply conditions (e.g., quantity and/or the concession of an exclusive territory to the retailer), when the retailer still has to invest in the handling, proper storage and promotion of the manufacturer's product. I next present the model.

Players And Sequence of events. Consider a principal and an agent who initially contract, knowing that the principal may later wish to deal with an external party instead. If they agree on a contract, a relationship is formed. If not, the principal and agent obtain their reservation payoffs (which are the expected value of dealing later with an external party and zero, respectively) and the game ends.

Once a relationship is formed, it evolves in three stages: $(i)$ an investment stage, in which the agent has the opportunity to make a relationship-specific investment $a \in \mathcal{A} \subseteq \mathbb{R}_{0}^{+}$; (ii) a renegotiation stage, which occurs after uncertainty about trade valuations is realized and where the principal and the agent renegotiate the terms of the initial contract; and (iii) a trading stage. Trade between the principal and the agent may never occur. At the renegotiation stage, parties may decide not to deal with each other if after uncertainty is resolved it is actually more efficient for the principal to trade with an external party than with the agent. The sequence of events is illustrated in Figure 1.

PAYOFfs. The parties' payoffs are quasi-linear in money. The agent's payoff is additive in the investment cost, which is denoted by $\psi(a)$ and assumed to be increasing in $a$. In addition to any money transfers, if at the trading stage the principal and agent trade with each other, 
they obtain values of $v_{P}$ and $v_{A}$, respectively. For future convenience, the value of trade between the principal and the agent is denoted $V \equiv v_{P}+v_{A} \cdot{ }^{4}$ The value of trade between the principal and an external party is denoted by $V_{E}$. For simplicity, I assume that $V_{E}$ is always non-negative.

Information. During the contracting and investment stages (ex-ante) trade valuations are still uncertain, but the principal is better informed about them than the agent. This is formalized by assuming that the principal knows the true state of the world $\theta \in \Theta \equiv\left\{\theta_{L}, \theta_{H}\right\}$, while the agent knows only its prior probability $p(\theta)$; and by assuming that the joint distribution of the valuations $v_{P}, v_{A}$ and $V_{E}$ depends not only on the agent's investment $a$ but also on state $\theta$, i.e., $\left(v_{P}, v_{A}, V_{E}\right) \sim F(. \mid a, \theta)$. After the investment stage, but before renegotiation, uncertainty is realized and both the principal and agent observe the realization of valuations $v_{A}, v_{P}$ and $V_{E}$. Hence, renegotiation and trading (ex-post) occur under symmetric information. Although observable by the parties, valuations cannot be verified by a court. Therefore, contracts that are directly contingent on valuations are not feasible.

Contracting. At the contracting stage, the principal has the opportunity to make a "take it or leave it" offer to the agent of a finite menu of contracts. If the agent accepts the menu, the principal herself then chooses a contract from the menu (throughout, the principal is feminine and the agent is masculine). This is the contract that governs the relationship between the principal and the agent. By allowing the principal to propose menus of contracts, I follow an approach similar to that in Maskin and Tirole (1992) when analyzing the problem of mechanism design by an informed principal.

The potentially contractible variables are: an up-front transfer $t$ from the agent to the principal, a quantity $q$, and a level of exclusivity $e$. The up-front transfer can take any real value, $t \in \mathbb{R}$. (A negative $t$ corresponds to a transfer from the principal to the agent.) Quantity $q$ denotes the probability that the principal and the agent must trade. The exclusivity variable $e$ denotes the probability that the agreement is exclusive; i.e., that the principal cannot trade with an external party. ${ }^{5}$ Throughout, the set of allowable quantities is denoted by $Q$ and that of allowable exclusivity levels by $E$. When both quantity and exclusivity are contractible, $Q=[0,1]$ and $E=[0,1]$. Noncontractible exclusivity is modeled by imposing $E=\{0\}$. A contract is an object of the form $c=(t, q, e) \in C$, where $C=\mathbb{R} \times Q \times E$. The agent's investment decision is not verifiable and therefore cannot be contractually specified. ${ }^{6}$

\footnotetext{
${ }^{4}$ Suppose, for example, that the principal is a buyer, the agent is seller with production cost $c$, and the buyer needs at most one unit of the seller's product. In this case, $v_{P}$ corresponds to the buyer's valuation of the seller's product and $v_{A}=-c$. The value created if the buyer and the seller trade is $V=v_{P}+v_{A}=v_{P}-c$.

${ }^{5}$ The quantity and exclusivity variables can be interpreted as proportions of trade capacity. Under this interpretation, quantity $q$ represents the proportion of the trade capacity of the principal that is contractually allocated to the agent, and exclusivity $e$ represents the proportion of the remaining $(1-q)$ of the trade capacity of the principal that cannot be traded with an external party. The assumption that $e$ is a proportion is not crucial. All the results in the paper hold if contracts can only prescribe full exclusivity $(e=1)$ or full non-exclusivity $(e=0)$.

${ }^{6}$ The existence of relationship-specific investments that are noncontractible has been the fundamental assumption in the hold-up problem literature. Relationship-specific investments often take a nonmonetary,
} 
Renegotiation. After observing the realization of the valuations, if the initial contract prescribes an inefficient level of trade, the principal and the agent renegotiate trade to the efficient level. The agent's investment decision is irreversible at this stage. As in Edlin and Reichelstein (1996), Che and Hausch (1999), Segal and Whinston (2000) and Segal and Whinston (2002), I assume that the bargaining shares of the principal and the agent during renegotiation are exogenously specified. More specifically, I assume that the principal and the agent equally divide their renegotiation surplus over the disagreement point, which is determined by the original contract. ${ }^{7}$ Thus, despite renegotiation, the original contract still matters because it affects the distribution of ex-post surplus, which in turn is important for surplus extraction by the principal and investment by the agent. Finally, I suppose that the external party with whom the principal can alternatively deal receives no surplus. This would be consistent, for instance, with a case of competition among many external parties who are willing to deal with the principal in the event she does not trade with the agent.

An implicit assumption in the model is that the agent gains some bargaining power during the relationship. This corresponds to situations where by investing in preparation for trade or by direct contact with the principal, the agent learns more about the principal (e.g., about technology employed, financial position, negotiation strategies) leaving him in a better position in future negotiations.

In the analysis that follows, the equilibrium concept used is the Perfect Bayesian Equilibrium $(\mathrm{PBE}){ }^{8}$

\subsection{Post-Renegotiation Payoffs, Expected Payoffs and Agent's Investment. At} the renegotiation stage, the principal and agent receive one half of the renegotiation surplus in addition to their disagreement payoffs. The disagreement payoffs of the principal and agent are the payoffs in the event they do not reach a renegotiation agreement and the initial contract is executed. The renegotiation surplus is the difference between the efficient total surplus and the sum of the disagreement payoffs. Since the disagreement payoffs (ignoring sunk investment costs) are $q v_{A}-t$ for the agent and $q v_{P}+(1-q)(1-e) V_{E}+t$ for the principal, and the efficient total surplus (also ignoring sunk investment costs) is $\max \left\{V, V_{E}\right\}$, the agent's post-renegotiation payoff given contract $c=(t, q, e)$ and $\alpha \equiv\left(a, v_{A}, v_{P}, V_{E}\right)$ is

\footnotetext{
intangible form, such as human capital investment. In these cases, it is difficult to contract on investmentrelated information.

${ }^{7}$ The assumption that the principal and the agent have equal bargaining shares at the renegotiation stage is not crucial. All the results remain unchanged if instead of $1 / 2$ we consider that the agent's bargaining share is $\lambda \in(0,1)$. The important assumption is that the agent has some (strictly positive) bargaining power at the renegotiation stage. Otherwise, his payoff would not depend on the private information of the principal, in which case there is no need for the principal to signal her private information to be able to extract surplus from the agent.

${ }^{8}$ See Fudenberg and Tirole (1991) for a precise definition of a PBE.
} 
given by

$$
\begin{aligned}
u_{A}(c ; \alpha) & =\left(q v_{A}-t\right)+\frac{1}{2}\left[\max \left\{V, V_{E}\right\}-\left(q v_{A}-t\right)-\left(q v_{P}+(1-q)(1-e) V_{E}+t\right)\right]-\psi(a) \\
(1) & =\frac{1}{2} \max \left\{V, V_{E}\right\}-\frac{1}{2}\left[q\left(v_{P}-v_{A}\right)+(1-q)(1-e) V_{E}\right]-t-\psi(a) .
\end{aligned}
$$

Similarly, the principal's post-renegotiation payoff can be written as

$$
u_{P}(c ; \alpha)=\frac{1}{2} \max \left\{V, V_{E}\right\}+\frac{1}{2}\left[q\left(v_{P}-v_{A}\right)+(1-q)(1-e) V_{E}\right]+t .
$$

Efficient renegotiation implies that the sum of the payoffs to principal and agent is always equal to efficient total surplus (hereinafter, total surplus), i.e., $u_{A}(c ; \alpha)+u_{P}(c ; \alpha)=s(\alpha)$, for all $c$ and $\alpha$, where $s(\alpha)=\max \left\{V, V_{E}\right\}-\psi(a)$.

Since the analysis will focus on the equilibrium of the contracting game between the principal and the agent, which occurs before uncertainty is resolved, it is convenient to obtain their ex-ante expected payoffs. The expected payoffs of the principal and agent are both functions of the contract $c$ and the agent's investment level $a$. However, since at the contracting and investment stages the principal knows $\theta$ and the agent does not, the expected payoff of the principal is a direct function of $\theta$, while the expected payoff of the agent is a function of his beliefs about $\theta$. More specifically, expected payoffs are given by

$$
U_{A}\left(c ; a \mid b_{H}\right)=\left(1-b_{H}\right) \mathbb{E}\left[u_{A} \mid a, \theta_{L}\right]+b_{H} \mathbb{E}\left[u_{A} \mid a, \theta_{H}\right]
$$

and

$$
U_{P}(c ; a \mid \theta)=\mathbb{E}\left[u_{P} \mid a, \theta\right], \text { all } \theta \in \Theta,
$$

where $b_{H} \in[0,1]$ represents the agent's belief that $\theta=\theta_{H}$. With a slight abuse of notation, $U_{A}(c ; a \mid 0)$ and $U_{A}(c ; a \mid 1)$ will be frequently denoted by $U_{A}\left(c ; a \mid \theta_{L}\right)$ and $U_{A}\left(c ; a \mid \theta_{H}\right)$, respectively.

The expected total surplus given investment $a$ and state $\theta$ is denoted by $S(a, \theta) \equiv \mathbb{E}[s(\alpha) \mid$ $a, \theta]$. From the fact that $u_{A}(c ; \alpha)+u_{P}(c ; \alpha)=s(\alpha)$ for all $c$ and $\alpha$, it follows that for any $\theta \in \Theta$ and $a \in \mathcal{A}$,

$$
U_{A}(c ; a \mid \theta)+U_{P}(c ; a \mid \theta)=S(a, \theta) \text { for all } c \in C .
$$

This property of the expected payoffs will be extensively used in the analysis of the equilibrium outcomes.

The first-best level of investment given state $\theta_{j}$, denoted by $a_{j}^{0}$, is the investment that maximizes total expected surplus, i.e.,

$$
a_{j}^{0} \equiv \underset{a \in \mathcal{A}}{\arg \max } S\left(a, \theta_{j}\right) .
$$

The agent's investment decision, denoted by $a^{*}\left(c, b_{H}\right)$, is the investment level that maximizes his expected payoff given contract $c$ and beliefs $b_{H}$, i.e.,

$$
a^{*}\left(c, b_{H}\right) \equiv \underset{a \in \mathcal{A}}{\arg \max } U_{A}\left(c ; a \mid b_{H}\right) .
$$


It is assumed that $S(a, \theta)$ and $U_{A}(c ; a \mid \theta)$ are concave in $a$ for all $\theta \in \Theta$, and that both $a_{j}^{0}$ and $a^{*}\left(c, b_{H}\right)$ are interior to $\mathcal{A}$. It is also assumed that $S(a, \theta)$ is differentiable in $a$ and $U_{A}(c ; a \mid \theta)$ is twice continuously differentiable in $a$ for all $\theta \in \Theta .^{9}$

\section{Internal Information and Exclusives: An Irrelevance Result}

I begin the analysis by showing that when the principal has no private information about her value of trade with the external parties $V_{E}$, then contracting on exclusivity does not expand the set of equilibrium outcomes. More specifically, I show that for any equilibrium when the contract space is $C=R \times Q \times E$, there is an equilibrium with identical expected payoffs and identical agent investment when the contract space is $C^{\prime}=R \times Q \times\{0\}$. For future reference, equilibria satisfying this property are called outcome equivalent.

This result is established here for expositional convenience. Specifically, because it will be useful in the next section and because it holds regardless of the way in which the agent's investment $a$ and the state $\theta$ affect the distribution of internal values $v_{A}$ and $v_{P}$-effects about which I will be more specific further on. Hereinafter, let $F_{V_{E}}(. \mid \theta)$ denote the marginal cumulative distribution function of $V_{E}$ given state $\theta .{ }^{10}$

Proposition 1 (Irrelevance Result). Suppose that the principal's private information does not include information about the principal's value of trade with external parties, i.e., $F_{V_{E}}(. \mid$ $\theta)=F_{V_{E}}($.$) for all \theta \in \Theta$. Then, exclusivity has no effect on the set of equilibrium outcomes: for any equilibrium when the contract space is $C=R \times Q \times E$, there is an outcome equivalent equilibrium when the contract space is $C^{\prime}=R \times Q \times\{0\}$.

Proof. See Appendix B.

There are two crucial points in understanding this result. First, since investment affects internal values only, there is no cross effect between investment and exclusivity in the payoff functions. This implies that exclusivity has no direct effect on the agent's investment decision. Second, since information is only about internal values, there is also no cross effect between exclusivity and private information $\theta$ in the expected payoff functions of the principal and the agent. In other words, the expected payoffs of the principal and the agent do not satisfy the single crossing property with respect to exclusivity. Thus, for given beliefs, the principal can exchange exclusivity by up-front transfer in the contract and still generate the same expected payoffs and the same agent's investment decision.

The irrelevance result in this section extends that in Segal and Whinston (2000) to a setting with asymmetric information. In that paper, the authors show that exclusivity has no effect on investment decisions when investment affects only internal values. Proposition 1 implies

\footnotetext{
${ }^{9}$ Concavity of $S(a, \theta)$ and $U_{A}(c ; a \mid \theta)$ in $a$ ensures that $a^{*}\left(c, b_{H}\right)$ and $a_{j}^{0}$ are unique. Differentiability of $S(a, \theta)$ and $U_{A}(c ; a \mid \theta)$ in $a$ and the fact that $a^{*}\left(c, b_{H}\right)$ and $a_{j}^{0}$ are interior to $\mathcal{A}$ imply that $a^{*}\left(c, b_{H}\right)$ and $a_{j}^{0}$ are characterized by the usual first-order conditions. Finally, the fact that $U_{A}(c ; a \mid \theta)$ is twice continuously differentiable in $a$ ensures that $a^{*}\left(c, b_{H}\right)$ changes smoothly with the contractual variables.

${ }^{10}$ The agent's investment does not affect this distribution because it is a relationship-specific investment.
} 
not only that exclusivity has no effect on investment decisions when investment affects only internal values, but also that exclusivity has no effect on surplus extraction (through signalling information) when private information is only about values internal to the relationship.

\section{Contractual Signalling and Relationship-Specific Investment}

In this section, I characterize equilibrium contracting between the principal and the agent and equilibrium agent's investment. As a consequence of ex-post renegotiation, trade is always efficient. This is because the levels of trade and exclusivity prescribed in the initial contract can always be changed (without cost) to their efficient levels after uncertainty about valuations has vanished. This holds regardless of the contract agreed on by the principal and the agent at the initial contracting stage. In contrast, the agent's investment decision is irreversible at the renegotiation stage. Hence, efficiency of investment is not ensured by renegotiation. In fact, it is because of ex-post renegotiation that a problem of hold-up in investment emerges.

The literature on the hold-up problem with symmetric information at the contracting stage shows that the inefficiency of investment can be resolved (or mitigated) if parties choose a contract that provides the right incentives to invest. In our setting, because of asymmetry of information, the principal uses the contract not only to provide incentives to invest, but also to signal information to the agent in order to extract surplus. As we shall see below, these two roles of contracting can conflict with one another.

I first analyze, as a benchmark, the case of contracting under symmetric information. I then consider the case in which quantity is contractible, but not exclusivity. Finally, I analyze the case in which both quantity and exclusivity are contractible. By comparing these two last cases, one obtains that in contrast to the result in the previous section, contractibility of exclusivity affects equilibrium outcomes and the efficiency of investment when the principal's private information is about the value of her outside option.

Before proceeding the analysis, some more structure about the nature of both the principal's private information and the agent's investment is introduced.

Agent Investment and Information Specifications. In the reminder of the paper it is assumed that the agent's investment affects only his value of trade with the principal. Specifically, that this value of trade is given by the non-stochastic increasing function $v_{A}(a)$. This type of investment as been referred in the literature as selfish investment. ${ }^{11}$

Regarding information, the following two forms of the principal's private information are considered:

\footnotetext{
${ }^{11}$ Concentrating on the case of selfish investment, as opposed to the case of cooperative investment (i.e., $a$ affects both the principal and the agent's valuations), allows us to better assess the effect of asymmetry of information at the contracting stage on efficiency of investment. In contrast with the case of selfish investment, a contract ensuring efficient cooperative investment may not exist even when information is symmetric at the contracting stage (see for example Che and Hausch, 1999).
} 
(i) Private information about $v_{P}: F_{v_{P}}\left[. \mid \theta_{H}\right]$ strictly first-order stochastically dominates $F_{v_{P}}\left[. \mid \theta_{L}\right]$, and $V_{E}$ and $v_{A}(a)$ do not depend on $\theta$; and

(ii) Private information about $V_{E}: F_{V_{E}}\left[\cdot \mid \theta_{L}\right]$ strictly first-order stochastically dominates $F_{V_{E}}\left[. \mid \theta_{H}\right]$, and $v_{P}$ and $v_{A}(a)$ do not depend on $\theta$.

For simplicity of exposition, it is assumed that there is ex-ante uncertainty only about the trade valuation about which the principal has private information. Thus, when the principal's private information is about $v_{P}$ (resp. $V_{E}$ ) only the trade valuation $v_{P}$ (resp. $V_{E}$ ) is uncertain ex-ante. All the results in the paper continue to hold if this assumption is relaxed.

A notion that will be useful in the remainder of the paper is that of probability of success of the relationship. This is the ex-ante probability that the principal and the agent trade. Efficiency of ex-post renegotiation implies that if trade between the principal and an external party creates more value than trade between the principal and the agent, the principal and the agent agree not to trade with each other. Thus, the probability of success of the relationship is the ex-ante probability that the value of trade $V(a) \equiv v_{A}(a)+v_{P}$ is greater than the value of trade $V_{E}$. Because this probability depends on both the agent's investment $a$ and the state $\theta$, it is denoted by $P_{s}(a, \theta)$.

Given the above agent's investment and information specifications, we can further characterize the probability of success of the relationship, the agent's investment decision and the way the agent's investment affects the principal's expected payoff. For future convenience, this is done here.

The probability of success of the relationship. The probability of success of the relationship $P_{s}(a, \theta)$ is always bigger in state $\theta_{H}$ than it is in state $\theta_{L}$, for each level of investment $a$. That is,

$$
P_{s}\left(a, \theta_{H}\right) \geq P_{s}\left(a, \theta_{L}\right) \text { for all } a \in \mathcal{A} \text {. }
$$

Furthermore, from the fact that $v_{A}(a)$ is an increasing function of $a$, it follows that $P_{s}(a, \theta)$ is increasing in $a$ for all $\theta \in \Theta$.

Agent's investment decision. Given contract $c$ and belief $b_{H}$, the agent chooses investment so as to maximize his expected payoff $U_{A}\left(c ; a \mid b_{H}\right)$. Under the above investment and information specifications

(5) $U_{A}(c ; a \mid \theta)=\frac{1}{2} \mathbb{E}\left[\max \left\{V(a), V_{E}\right\} \mid \theta\right]-\frac{1}{2} \mathbb{E}\left[q\left(v_{P}-v_{A}(a)\right)+(1-q)(1-e) V_{E} \mid \theta\right]-\psi(a)-t$.

The agent's optimal investment is characterized by the first-order condition

$$
\frac{1}{2} v_{A}^{\prime}(a)\left[\left(1-b_{H}\right) P_{s}\left(a, \theta_{L}\right)+b_{H} P_{s}\left(a, \theta_{H}\right)+q\right]=\psi^{\prime}(a) .
$$

From (6), one obtains that the agent's investment decision depends on contract $c$ only through quantity $q$. Thus, henceforth I use $a^{*}\left(c, b_{H}\right)$ and $a^{*}\left(q, b_{H}\right)$ interchangeably. Moreover, since $P_{s}\left(a, \theta_{H}\right) \geq P_{s}\left(a, \theta_{L}\right)$ for all $a \in \mathcal{A}$, the agent's investment is increasing in his belief $b_{H}$. Intuitively, agents who believe that the trade relationship with the principal is more likely to succeed are willing to invest more in it. Finally, note that the agent's investment decision 
increases with the contracted quantity $q$. Intuitively, when facing a contract specifying a high quantity level, the agent knows that with high probability his disagreement payoff at the renegotiation stage will be his value of trade with the principal $v_{A}(a)$. Therefore, in that case, his incentives to invest are also high in order to protect his disagreement payoff.

I summarize these results in the following Lemma.

Lemma 1. The agent's investment decision $a^{*}\left(q, b_{H}\right)$ is increasing with contracted quantity $q$ and with beliefs $b_{H}$.

Agent's investment and principal's payoff. Although the agent's investment does not affect the principal's value of trade with the agent $v_{P}$, it affects her expected payoff:

$$
U_{P}(c ; a \mid \theta)=\frac{1}{2} \mathbb{E}\left[\max \left\{V(a), V_{E}\right\} \mid \theta\right]+\frac{1}{2} \mathbb{E}\left[q\left(v_{P}-v_{A}(a)\right)+(1-q)(1-e) V_{E} \mid \theta\right]+t .
$$

In fact, it does so through two different channels: by affecting the total surplus (the first term in (7)), which is a positive effect; and by affecting the agent's disagreement payoff $\left(-q v_{A}(a)\right.$ in the second term in (7)), which is a negative effect. Differentiating $U_{P}(c ; a \mid \theta)$ with respect to $a$, we obtain

$$
\frac{1}{2} v_{A}^{\prime}(a)\left[P_{s}(a, \theta)-q\right]
$$

Therefore, which of the effects is the dominant depends on the relative values of the contracted quantity $q$ and the probability of success of the relationship $P_{s}(a, \theta)$. In particular, when contracted quantity is zero, the "total surplus effect" dominates, and therefore the principal's payoff is increasing with investment. When contracted quantity is one, the reverse occurs. Finally, note from (8) that the principal's payoff responds more positively to investment when the probability of success of the relationship is high. For future convenience, I state this result in the following Lemma.

Lemma 2. The expected payoff of the principal is supermodular in $(\theta, a)$. Specifically, for all $a_{1}, a_{2} \in \mathcal{A}$ such that $a_{2} \geq a_{1}$ and for all $c \in C$,

$$
U_{P}\left(c ; a_{2} \mid \theta_{H}\right)-U_{P}\left(c ; a_{1} \mid \theta_{H}\right) \geq U_{P}\left(c ; a_{2} \mid \theta_{L}\right)-U_{P}\left(c ; a_{1} \mid \theta_{L}\right) .
$$

4.1. A Benchmark Case: Symmetric Information Contracting. Suppose that both the principal and the agent know $\theta$ at the contracting and investment stages. In this symmetric information environment, the contracting problem faced by the principal consists of choosing the contract that maximizes her expected payoff taking into account the individual rationality constraint and the investment decision of the agent, i.e., given $\theta$ the principal solves

$$
\begin{array}{ll}
\max _{c, a} & U_{P}(c ; a \mid \theta) \\
\text { s.t. } & (i) \quad U_{A}(c ; a \mid \theta) \geq 0 \\
& (i i) \quad a \in \underset{a^{\prime} \in \mathcal{A}}{\arg \max } U_{A}\left(c ; a^{\prime} \mid \theta\right)
\end{array}
$$


Because $U_{P}(c ; a \mid \theta)=U_{P}(0, q, e ; a \mid \theta)+t$ and $U_{A}(c ; a \mid \theta)=U_{A}(0, q, e ; a \mid \theta)-t$ for all $c \in C, a \in \mathcal{A}$ and $\theta \in \Theta$, constraint $(i)$ must bind in any solution to this problem. Moreover, since ex-post renegotiation implies that $U_{P}(c ; a \mid \theta)+U_{A}(c ; a \mid \theta)=S(a, \theta)$, the principal's problem can be rewritten as

$$
\begin{aligned}
& \max _{q, e, a} S(a, \theta) \\
& \text { s.t. } \quad a \in \underset{a^{\prime} \in \mathcal{A}}{\arg \max } U_{A}\left(0, q, e ; a^{\prime} \mid \theta\right)
\end{aligned}
$$

Hence, the principal always proposes the contract that induces the agent to invest as efficiently as possible and uses the transfer $t$ to extract all the surplus from the agent. We shall see that this contrasts with the asymmetric information environment where, when choosing the contract, the principal also takes into account the need to signal her type in order to extract surplus.

The first-best level of investment is implementable in the case of symmetric information. Note that, the first-best investment $a_{j}^{0}$ associated with state $\theta_{j}$ solves

$$
\max _{a \in \mathcal{A}} S\left(a, \theta_{j}\right)=\max _{a \in \mathcal{A}} \mathbb{E}\left[\max \left\{V(a), V_{E}\right\} \mid \theta_{j}\right]-\psi(a) .
$$

Because $S(a, \theta)$ is differentiable in $a$ and the first-best investment is interior, $a_{j}^{0}$ satisfies the first-order condition

$$
v_{A}^{\prime}\left(a_{j}^{0}\right) P_{s}\left(a_{j}^{0}, \theta_{j}\right)=\psi^{\prime}\left(a_{j}^{0}\right)
$$

In a similar way, from (6) we obtain that the agent's investment $a$ when he knows state $\theta$ with certainty satisfies the first-order condition

$$
\frac{1}{2} v_{A}^{\prime}(a)\left[P_{s}(a, \theta)+q\right]=\psi^{\prime}(a) .
$$

Comparing (10) and (11), we obtain that the principal can induce the agent to invest the first-best investment in state $\theta_{j}$ by choosing

$$
q=P_{s}\left(a^{0}\left(\theta_{j}\right), \theta_{j}\right) \equiv q_{j}^{0},
$$

i.e., by setting in state $\theta_{j}$ the contracted quantity equal to the probability of success of the relationship evaluated at the first-best investment $a_{j}^{0}$. Thus, when information is symmetric, investment is efficient in equilibrium (first-best) and the principal receives the first-best total expected surplus $S\left(a_{j}^{0}, \theta_{j}\right)$, for all $j \in\{L, H\}$.

I next come back to the case of the principal with private information and characterize equilibrium. In this case, surplus extraction by the principal is more difficult than when information is symmetric because the principal needs to signal her information. I start by analyzing the case where quantity is contractible, but not exclusivity. I then compare it with the case where both quantity and exclusivity are contractible. 
4.2. Quantity Contracts. Let us focus first on the case of quantity contracts. Suppose that $E=\{0\}$, meaning that exclusivity is not contractible. Thus, a contract is a transfer-quantity pair, i.e., $c=(t, q)$. These contracts are often referred to as specific performance contracts. The analysis and results in this section hold for both the case of private information about $v_{P}$ and that of private information about $V_{E}$. The main purpose here is to characterize equilibria and to show the existence of inefficient equilibria in terms of investment. I proceed as follows. I first define and characterize a specific type of allocation - the best separating allocation. I then use it to characterize equilibria.

Formally, a menu of contracts $\widehat{m}=\left\{\widehat{c}_{L}, \widehat{c}_{H}\right\}$ constitutes the best separating allocation if and only if, for all $j \in\{L, H\}$,

$$
\begin{aligned}
& U_{P}\left(\widehat{c}_{j} ; a^{*}\left(\widehat{c}_{j}, \beta_{j}\right) \mid \theta_{j}\right)=\max _{\left\{c_{L}, c_{H}\right\}} U_{P}\left(c_{j} ; a^{*}\left(c_{j}, \beta_{j}\right) \mid \theta_{j}\right) \\
& \text { s.t. } \quad(i) \quad U_{P}\left(c_{L} ; a^{*}\left(c_{L}, 0\right) \mid \theta_{L}\right) \geq U_{P}\left(c_{H} ; a^{*}\left(c_{H}, 1\right) \mid \theta_{L}\right) \quad \operatorname{IC}\left(\theta_{L}\right) \\
& \text { (ii) } U_{P}\left(c_{H} ; a^{*}\left(c_{H}, 1\right) \mid \theta_{H}\right) \geq U_{P}\left(c_{L} ; a^{*}\left(c_{L}, 0\right) \mid \theta_{H}\right) \quad \operatorname{IC}\left(\theta_{H}\right) \\
& \text { (iii) } U_{A}\left(c_{r} ; a^{*}\left(c_{r}, \beta_{r}\right) \mid \theta_{r}\right) \geq 0 \quad \text { for all } r=L, H \quad \operatorname{IR}\left(\theta_{r}\right)
\end{aligned}
$$

where $\beta_{L}=0$ and $\beta_{H}=1$. That is, each type of principal maximizes (in independent maximizations) her own payoff within the set of menus that are incentive compatible for the principal, and regardless of the principal's type, yield the agent a non-negative payoff. Note two things. First, incentive compatibility depends on the agent's investment decisions following the principal's choice of contract $c$ in $m=\left\{c_{L}, c_{H}\right\}$, which in turn depends on the agent's beliefs. In the definition of the best separating allocation we implicitly assume that the agent's beliefs are: $b_{H}=0$ after observing contract choice $c_{L}$ and $b_{H}=1$ after observing contract choice $c_{H}$ (hereinafter, separating beliefs). Second, a best separating allocation is itself incentive compatible given these separating beliefs. These two facts have two implications. First, although obtaining the best separating allocation involves performing two independent maximizations (one for the principal of type $\theta_{L}$ and another one for the principal of type $\left.\theta_{H}\right)$, the best separating allocation $\widehat{m}=\left\{\widehat{c}_{L}, \widehat{c}_{H}\right\}$ solves problem 12 for both types. Second, following the proposal of a best separating allocation $\widehat{m}=\left\{\widehat{c}_{L}, \widehat{c}_{H}\right\}$ by the principal, there is always a continuation equilibrium in which the agent accepts the proposal and the principal of type $\theta_{j}$ chooses contract $\widehat{c}_{j}$ from $\widehat{m}$, for all $j \in\{L, H\}$. These two properties will be used below to obtain the best separating allocation and to characterize equilibrium contracting and investment.

In the rest of the paper, I impose the following condition.

Condition 1. $U_{A}\left(c ; a^{*}\left(c, b_{H}\right) \mid b_{H}\right)$ is increasing in $b_{H}$ when $c$ specifies quantity $q_{L}^{0} \cdot{ }^{12}$

\footnotetext{
${ }^{12}$ This condition holds whenever $q_{L}^{0} \leq \bar{x}\left(q_{L}^{0}, 0\right)$, where $\bar{x}\left(q, b_{H}\right)$ is the quantity level for which the expected payoffs of the agent in both states $\theta_{L}$ and $\theta_{H}$, given investment $a^{*}\left(q, b_{H}\right)$, are the same, i.e., $\bar{x}\left(q, b_{H}\right)$ : $U_{A}\left(0, \bar{x}\left(q, b_{H}\right) ; a^{*}\left(q, b_{H}\right) \mid \theta_{L}\right)=U_{A}\left(0, \bar{x}\left(q, b_{H}\right) ; a^{*}\left(q, b_{H}\right) \mid \theta_{H}\right)$.
} 
Condition 1 allows us to concentrate our attention on the payoffs in state $\theta_{H}$. As we will see below, this condition has two implications. First, the payoff of the principal in state $\theta_{L}$ associated with the best separating allocation is the first-best total surplus $S\left(a_{L}^{0}, \theta_{L}\right)$. Second, in state $\theta_{L}$ the principal can ensure herself at least $S\left(a_{L}^{0}, \theta_{L}\right)$, regardless of the agent's beliefs.

I now characterize the best separating allocation. I start by analyzing the payoff of the principal of type $\theta_{L}$ and the contract $\widehat{c}_{L}$ associated with it.

Lemma 3. The payoff of the principal of type $\theta_{L}$ associated with the best separating allocation is $S\left(a_{L}^{0}, \theta_{L}\right)$. Moreover, contract $\widehat{c}_{L}=\left(\widehat{t}_{L}, \widehat{q}_{L}\right)$ is given by $\widehat{q}_{L}=q_{L}^{0}$ and $\widehat{t}_{L}=U_{A}\left(0, q_{L}^{0} ; a_{L}^{0} \mid \theta_{L}\right)$.

Proof. See Appendix B.

Under Condition 1, given the separating beliefs, it is always possible to construct an incentive compatible menu of contracts satisfying the agent's individual rationality constraint in both states $\theta_{L}$ and $\theta_{H}$, which leaves the principal of type $\theta_{L}$ with the first-best total surplus $S\left(a_{L}^{0}, \theta_{L}\right)$. The only contract compatible with the principal's payoff $S\left(a_{L}^{0}, \theta_{L}\right)$ and non-negativity of the agent's expected payoff given state $\theta_{L}$, is the contract that specifies $q_{L}=q_{L}^{0}$ and transfer $t_{L}$ such that the principal extracts all the surplus from the agent in state $\theta_{L}$ (i.e., $\operatorname{IR}\left(\theta_{L}\right)$ binds). ${ }^{13}$ Thus, in the best separating allocation, this is the contract associated with the principal of type $\theta_{L}$.

Next, I analyze the payoff of the principal of type $\theta_{H}$ and the contract $\widehat{c}_{H}$ associated with the best separating allocation. Given Lemma 3 and the observation that the best separating allocation $\left\{\widehat{c}_{L}, \widehat{c}_{H}\right\}$ has the property that it solves (12) for both types of principal, we can restrict without loss of generality to menus of the type $\left\{\widehat{c}_{L}, c_{H}\right\}$ when solving for (12) for the principal of type $\theta_{H}$. Thus, finding contract $\widehat{c}_{H}$ and the payoff of the principal of type $\theta_{H}$ associated with the best separating allocation consists of finding the contract $c_{H}=\left(t_{H}, q_{H}\right)$ that solves

\section{Problem 2.}

$$
\begin{aligned}
& \max _{t_{H}, q_{H}} U_{P}\left(0, q_{H} ; a^{*}\left(q_{H}, 1\right) \mid \theta_{H}\right)+t_{H} \\
& \text { s.t. } \quad(i) \quad S\left(a_{L}^{0}, \theta_{L}\right) \geq U_{P}\left(0, q_{H} ; a^{*}\left(q_{H}, 1\right) \mid \theta_{L}\right)+t_{H} \quad\left(\operatorname{IC}\left(\theta_{L}\right)\right) \\
& \text { (ii) } U_{P}\left(0, q_{H} ; a^{*}\left(q_{H}, 1\right) \mid \theta_{H}\right)+t_{H} \geq U_{P}\left(\widehat{c}_{L} ; a^{*}\left(\widehat{c}_{L}, 0\right) \mid \theta_{H}\right) \quad\left(I C\left(\theta_{H}\right)\right) \\
& \text { (iii) } U_{A}\left(0, q_{H} ; a^{*}\left(q_{H}, 1\right) \mid \theta_{H}\right)-t_{H} \geq 0 \quad\left(\operatorname{IR}\left(\theta_{H}\right)\right)
\end{aligned}
$$

Problem 2 consists of finding the contract that maximizes the payoff of the principal in state $\theta_{H}$, assuming that the agent knows the true state of the world (due to separation, the agent correctly infers $\theta$ from the principal's contract choice). The first two constraints, the usual IC constraints, impose that each type of principal prefers not to deviate and mimic the

\footnotetext{
${ }^{13}$ Observe that, given state $\theta_{L}$, if the principal's payoff equals the first-best total surplus, then the agent's payoff is non-negative only if investment is efficient, i.e., $a_{L}^{0}$. Moreover, when the agent's beliefs are $b_{H}=0$, only a contract specifying quantity $q_{L}=q_{L}^{0}$ induces the agent to choose the first-best investment $a_{L}^{0}$.
} 


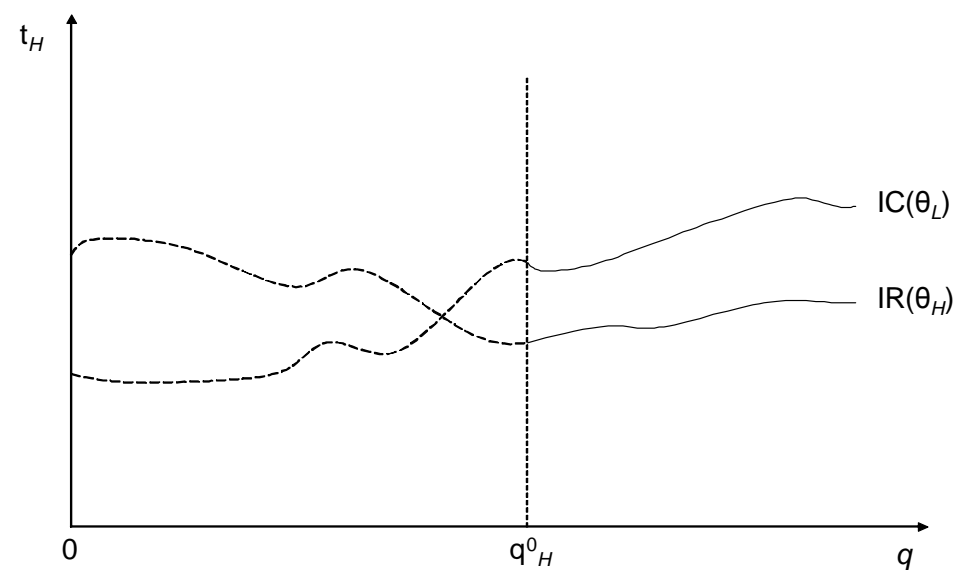

Figure 2. Case 1 - the binding constraint when $q_{H}=q_{H}^{0}$ is $\operatorname{IR}\left(\theta_{H}\right)$.

other type; otherwise separation would not occur. Constraint $(i i i)$, the $\operatorname{IR}\left(\theta_{H}\right)$ constraint, imposes that the payoff of the agent who knows that the state is $\theta_{H}$ cannot be lower than his reservation value. For each quantity level $q_{H}$, constraints $\operatorname{IC}\left(\theta_{L}\right)$ and $\operatorname{IR}\left(\theta_{H}\right)$ impose an upper bound on the value of the up-front transfer $t_{H}$.

Deriving the solution to Problem 2 offers important insights regarding the crucial effects leading to the existence of inefficient equilibria, and we shall do so here.

In any solution to Problem 2, at least one of the constraints $\operatorname{IC}\left(\theta_{L}\right)$ or $\operatorname{IR}\left(\theta_{H}\right)$ is binding. ${ }^{14}$ Suppose that this were not the case; then it would be possible to increase $t_{H}$ by an arbitrarily small amount $\epsilon>0$ and still have all the constraints in the problem satisfied (including $\left.\operatorname{IC}\left(\theta_{H}\right)\right)$ while increasing the objective function, which would be a contradiction.

Let us now be more specific about which of the constraints $\operatorname{IC}\left(\theta_{L}\right)$ or $\operatorname{IR}\left(\theta_{H}\right)$ is binding. There are two possible cases, which I consider separately.

Case 1: The binding constraint when $q_{H}=q_{H}^{0}$ is $\operatorname{IR}\left(\theta_{H}\right)$. This case is depicted in Figure 2. When $\operatorname{IR}\left(\theta_{H}\right)$ is the binding constraint at $q_{H}=q_{H}^{0}$, first-best investment and full surplus extraction in both states $\theta_{L}$ and $\theta_{H}$ is incentive compatible. Therefore, the solution to Problem 2 involves $q_{H}=q_{H}^{0}$ and $t_{H}$ such that $\operatorname{IR}\left(\theta_{H}\right)$ binds. This implies that the payoff of the principal of type $\theta_{H}$ associated with the best separating allocation is the first-best total surplus in state $\theta_{H}, S\left(a_{H}^{0}, \theta_{H}\right)$, and $\widehat{c}_{H}=\left(\widehat{t}_{H}, q_{H}^{0}\right)$ where $\widehat{t}_{H}=U_{A}\left(0, q_{H}^{0} ; a^{*}\left(q_{H}^{0}, 1\right) \mid \theta_{H}\right)$. In this case, there is no conflict between surplus extraction and efficiency: the best separating allocation is characterized by full surplus extraction and full efficiency in terms of the agent's investment decision.

Case 2: The binding constraint when $q_{H}=q_{H}^{0}$ is $\operatorname{IC}\left(\theta_{L}\right)$. This case is depicted in Figure 3. To study the solution to Problem 2 in this case, I first analyze which constraint is binding for $q_{H} \in\left[q_{H}^{0}, 1\right]$.

\footnotetext{
${ }^{14}$ Usually in this type of problem constraint $\operatorname{IC}\left(\theta_{H}\right)$ is not binding. Therefore, it is omitted during the determination of the solution to the problem and checked to be satisfied ex-post. I do this in Appendix A (see Lemma 7).
} 


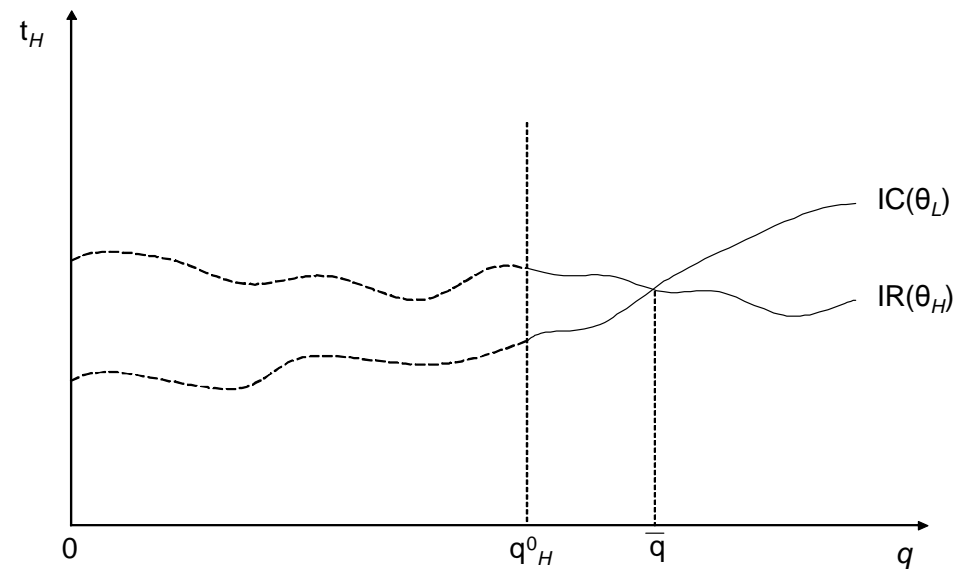

Figure 3. Case 2 - the binding constraint when $q_{H}=q_{H}^{0}$ is $\operatorname{IC}\left(\theta_{L}\right)$.

Lemma 4. Constraints $I C\left(\theta_{L}\right)$ and $\operatorname{IR}\left(\theta_{H}\right)$ intersect only once in the interval $\left[q_{H}^{0}, 1\right]$. Denote the intersection quantity by $\bar{q}$. Then, $I C\left(\theta_{L}\right)$ is the binding constraint for $q_{H} \in\left[q_{H}^{0}, \bar{q}\right]$ and $\operatorname{IR}\left(\theta_{H}\right)$ is the binding constraint for $q_{H} \in[\bar{q}, 1]$.

Proof. See Appendix B.

Obtaining the solution to Problem 2 involves determining how the expected payoff of the principal of type $\theta_{H}$ (the objective function) evolves with $q_{H}$ along the relevant binding constraint.

For $q_{H}>\bar{q}$, the binding constraint is $\operatorname{IR}\left(\theta_{H}\right)$, so there is full surplus extraction and the payoff of the principal is given by $S\left(a^{*}\left(q_{H}, 1\right), \theta_{H}\right)$. Observe that the expected total surplus $S\left(a^{*}\left(q_{H}, 1\right), \theta_{H}\right)$ reaches its maximum value at $q_{H}=q_{H}^{0}$, since $a^{*}\left(q_{H}^{0}, 1\right)=a_{H}^{0}$, which is the first-best investment in state $\theta_{H}$. Therefore, from concavity of $S\left(a, \theta_{H}\right)$ in investment $a$ and the fact that the agent's investment decision $a^{*}\left(q_{H}, 1\right)$ is increasing in $q_{H}$, it follows that $S\left(a^{*}\left(q_{H}, 1\right), \theta_{H}\right)$ decreases in $q_{H}$ for $q_{H} \geq \bar{q}$ (recall that $\bar{q} \geq q_{H}^{0}$ ). Thus, the payoff of the principal type $\theta_{H}$ decreases with $q_{H}$ in the interval $[\bar{q}, 1]$ and therefore a solution to Problem 2 must satisfy $q_{H} \leq \bar{q}$.

For $q_{H} \in\left[q_{H}^{0}, \bar{q}\right]$, the binding constraint is $\operatorname{IC}\left(\theta_{L}\right)$. To study how the expected payoff of the principal of type $\theta_{H}$ evolves with $q_{H}$ along the constraint $\operatorname{IC}\left(\theta_{L}\right)$, let $m\left(q_{H}\right)$ denote the function obtained by substituting $t_{H}$ in the expected payoff of the principal of type $\theta_{H}$ by its value when constraint $\operatorname{IC}\left(\theta_{L}\right)$ is binding, i.e.,

$$
m\left(q_{H}\right)=U_{P}\left(0, q_{H} ; a^{*}\left(q_{H}, 1\right) \mid \theta_{H}\right)-U_{P}\left(0, q_{H} ; a^{*}\left(q_{H}, 1\right) \mid \theta_{L}\right)+S\left(a_{L}^{0}, \theta_{L}\right) .
$$

Differentiating it with respect to $q_{H}$, we obtain

$$
\begin{aligned}
\frac{\partial m\left(q_{H}\right)}{\partial q_{H}}= & \frac{\partial}{\partial q_{H}}\left[U_{P}\left(0, q_{H} ; a^{*}\left(q_{H}, 1\right) \mid \theta_{H}\right)-U_{P}\left(0, q_{H} ; a^{*}\left(q_{H}, 1\right) \mid \theta_{L}\right)\right] \\
& +\frac{\partial}{\partial a}\left[U_{P}\left(0, q_{H} ; a^{*}\left(q_{H}, 1\right) \mid \theta_{H}\right)-U_{P}\left(0, q_{H} ; a^{*}\left(q_{H}, 1\right) \mid \theta_{L}\right)\right] \times \frac{\partial a^{*}\left(q_{H}, 1\right)}{\partial q_{H}} .
\end{aligned}
$$


Changing $q_{H}$ has a direct effect, which is given by the first term, and an indirect effect through investment that corresponds to the second term. The first term, which is equal to

$$
\frac{1}{2}\left[\mathbb{E}\left[v_{P} \mid \theta_{H}\right]-\mathbb{E}\left[v_{P} \mid \theta_{L}\right]\right] \geq 0
$$

in the case of private information about $v_{P}$, and to

$$
\frac{1}{2}\left[\mathbb{E}\left[V_{E} \mid \theta_{L}\right]-\mathbb{E}\left[V_{E} \mid \theta_{H}\right]\right] \geq 0
$$

in the case of private information about $V_{E}$, represents the direct surplus extraction effect: by increasing $q_{H}$, the principal of type $\theta_{H}$ can also increase the up-front transfer $t_{H}$ in a way that $\operatorname{IC}\left(\theta_{L}\right)$ continues to be satisfied and her total payoff increases. This effect stems from the fact that when holding the agent's investment fixed, the principal's expected payoff exhibits the single crossing property with respect to transfer and quantity, i.e., the marginal rate of substitution between transfer and quantity is bigger for the principal of type $\theta_{H}$ than it is for the principal of type $\theta_{L}$. The second term, which represents the indirect investment effect, is equal to

$$
v_{A}^{\prime}\left(a^{*}\left(q_{H}, 1\right)\right)\left[P_{s}\left(a^{*}\left(q_{H}, 1\right), \theta_{H}\right)-P_{s}\left(a^{*}\left(q_{H}, 1\right), \theta_{L}\right)\right] \times \frac{\partial a^{*}\left(q_{H}, 1\right)}{\partial q_{H}}
$$

and is also positive since $\partial a^{*}\left(q_{H}, 1\right) / \partial q_{H} \geq 0$ (see Lemma 1) and $P_{s}\left(a, \theta_{H}\right) \geq P_{s}\left(a, \theta_{L}\right)$ for all $a \in \mathcal{A}$. Intuitively, the investment effect is positive because the payoff of the principal of type $\theta_{H}$ is more sensitive to relationship-specific investment than the payoff of the principal of type $\theta_{L}$. Therefore, it is the principal of type $\theta_{H}$ who gains more by increasing quantity and inducing the agent to invest more.

Since the direct surplus extraction effect and the indirect investment effect are both positive, the expected payoff of the principal of type $\theta_{H}$ increases with contracted quantity when moving along the $\operatorname{IC}\left(\theta_{L}\right)$ constraint. This result, together with the fact that that payoff decreases with contracted quantity when moving along $\operatorname{IR}\left(\theta_{H}\right)$ when $q_{H}>\bar{q}$, implies that the solution to Problem 2 is given by $q_{H}=\bar{q} \cdot{ }^{15}$ Hence, in this case, the contract of the principal of type $\theta_{H}$ associated with the best separating allocation is $\widehat{c}_{H}=\left(\widehat{t}_{H}, \bar{q}\right)$, where $\widehat{t}_{H}$ is such that $\operatorname{IR}\left(\theta_{H}\right)$ binds. The payoff of the principal associated with this contract is $S\left(a^{*}(\bar{q}, 1), \theta_{H}\right)<S\left(a_{H}^{0}, \theta_{H}\right)$.

In contrast to Case 1, in this case the outcome associated with the best separating allocation is inefficient in terms of investment: in order to signal information to extract surplus, the principal sets an excessively high quantity $\left(\bar{q}>q_{H}^{0}\right)$, leading the agent to overinvest in the relationship. This completes the derivation of the best separating allocation. I now proceed to the characterization of equilibrium outcomes.

As argued above, following the proposal of a best separating allocation $\widehat{m}=\left\{\widehat{c}_{L}, \widehat{c}_{H}\right\}$ by the principal, there is a continuation equilibrium in which the agent accepts the principal's proposal and then the principal chooses contract $\widehat{c}_{L}$ if she is of type $\theta_{L}$ and contract $\widehat{c}_{H}$

\footnotetext{
${ }^{15}$ Since the expected payoff of the principal of type $\theta_{H}$ increases with quantity when moving along the $\operatorname{IC}\left(\theta_{L}\right)$ constraint, the solution to Problem 2 cannot involve a contract specifying a quantity smaller than $q_{H}^{0}$.
} 
if she is of type $\theta_{H}$. Hence, the remaining question is whether both types of principal proposing $\widehat{m}=\left\{\widehat{c}_{L}, \widehat{c}_{H}\right\}$ followed by this separating continuation equilibrium constitutes an equilibrium of the overall game, i.e., whether there exist beliefs and continuation equilibria off-the-equilibrium path such that no type of principal gains by deviating and proposing a menu $m^{\prime} \neq \widehat{m}$. The next proposition clarifies this question. In what follows, let $M$ denote the set of finite menus of contracts and $\widehat{U}_{P}\left(\theta_{L}\right)$ and $\widehat{U}_{P}\left(\theta_{H}\right)$ denote the principal's payoffsderived above - associated with the best separating allocation.

Proposition 2. If both types of principal propose a menu $m \in M$, followed by a continuation equilibrium (after menu proposal) in which the principal's payoffs $\widetilde{U}_{P}\left(\theta_{L}\right)$ and $\widetilde{U}_{P}\left(\theta_{H}\right)$ are such that $\widetilde{U}_{P}\left(\theta_{j}\right) \geq \widehat{U}_{P}\left(\theta_{j}\right)$ for all $j \in\{L, H\}$, then there are off-the-equilibrium path beliefs such that this proposal and continuation equilibrium constitutes an equilibrium outcome of the overall game.

Proof. See Appendix B.

Proposition 2 provides sufficient conditions for an equilibrium. Specifically, it ensures that both types of principal proposing a menu of contracts $m$, followed by a continuation equilibrium (after the menu proposal) in which the principal's payoffs Pareto dominate the payoffs associated with the best separating allocation constitutes an equilibrium.

An implication of Proposition 2 is that both types of principal proposing the best separating allocation, followed by the respective separating continuation equilibrium, always constitutes an equilibrium of the game. In particular, Proposition 2 establishes that inefficient equilibria exist. Among these are those in which the principal of type $\theta_{H}$ distorts the contracted quantity (relative to $q_{H}^{0}$, which is the quantity that induces the agent to invest efficiently in state $\left.\theta_{H}\right)$ in order to extract more surplus from the agent.

This result is important not only because of the specific efficiency implications that it has, but also because it emphasizes that surplus extraction and efficiency of investment can in fact conflict with one another when parties contract under asymmetric information. I next allow exclusivity to be contractible and investigate its role in mitigating this conflict.

4.3. Quantity and Exclusivity Contracts. Suppose now that both quantity and exclusivity are contractible, i.e., $Q=E=[0,1]$. In this case, a contract is triple $c=(t, q, e)$. Because of the irrelevance result of Proposition 1, contractibility of exclusivity does affect the set of equilibrium outcomes when the principal's private information is about $v_{P}$. Thus, in this section only the case where the principal's private information is about the external value $V_{E}$ is considered.

To characterize the equilibrium allocations and payoffs, I start by presenting in Lemma 5 lower bounds for the principal's equilibrium payoffs. Then, in Proposition 3, I present the equilibrium payoffs themselves and characterize equilibrium investments. 
Lemma 5. Suppose that quantity and exclusivity are contractible $(Q=E=[0,1])$. Then, in any equilibrium, the payoff of the principal of type $\theta_{j}$ is at least the first-best expected total surplus $S\left(a_{j}^{0}, \theta_{j}\right)$, for all $j \in\{L, H\}$.

Proof. See Appendix B.

Contractibility of exclusivity plays no role in ensuring to the principal of type $\theta_{L}$ the firstbest total surplus $S\left(a_{L}^{0}, \theta_{L}\right)$. Under Condition 1, the principal of type $\theta_{L}$ always achieves this payoff even if exclusivity is not contractible. In contrast, in the case of the principal of type $\theta_{H}$, it is the fact that exclusivity is contractible that allows the principal to construct a contract that guarantees her the first-best total surplus $S\left(a_{H}^{0}, \theta_{H}\right)$. Note that, we have just seen in the previous section that when exclusivity is not contractible, there exist equilibria in which the payoff of the principal of type $\theta_{H}$ is $S\left(a^{*}(\bar{q}, 1), \theta_{H}\right)<S\left(a_{H}^{0}, \theta_{H}\right)$.

To illustrate the role of exclusivity when the principal is of type $\theta_{H}$, consider the expected payoff of the agent given contract $(t=0, q, e)$, state $\theta$ and investment $a$. In the case of private information about the external value $V_{E}$, this payoff can be written as

$$
U_{A}(0, q, e ; a \mid \theta)=\frac{1}{2} \mathbb{E}\left[\max \left\{V(a), V_{E}\right\} \mid \theta\right]-\frac{1}{2}\left[q\left(v_{P}-v_{A}\right)+(1-q)(1-e) \mathbb{E}\left[V_{E} \mid \theta\right]-\psi(a) .\right.
$$

When the contract prescribes full exclusivity, i.e., $e=1$, the agent's expected payoff is affected by $\theta$ only through the term $\frac{1}{2} \mathbb{E}\left[\max \left\{V(a), V_{E}\right\} \mid \theta\right]$. Therefore, from the fact that the distribution of the external value $V_{E}$ in state $\theta_{L}$ first-order stochastically dominates that in state $\theta_{H}$, it follows that

$$
U_{A}\left(0, q, e=1 ; a \mid \theta_{L}\right) \geq U_{A}\left(0, q, e=1 ; a \mid \theta_{H}\right) \text { for all } a \in \mathcal{A} .
$$

Intuitively, when the principal promises full exclusivity, the agent is better off when the principal has a high outside option (state $\theta_{L}$ ), since he can appropriate part of it at the renegotiation stage by threatening to enforce the contract and prevent the principal from trading with third parties.

From (13), it follows that the agent's expected payoff $U_{A}\left(0, q, e=1 ; a^{*}\left(q, b_{H}\right) \mid b_{H}\right)$ is decreasing in his belief $b_{H}$, for any given quantity $q$. In particular, this holds for $q=q_{H}^{0}$. This implies that regardless of the agent's beliefs, he always accepts contract $\left(t, q_{H}^{0}, e=1\right)$ in which $t=U_{A}\left(0, q_{H}^{0}, 1 ; a^{*}\left(q_{H}^{0}, 1\right) \mid \theta_{H}\right)$, i.e., his expected payoff when his beliefs are $b_{H}=1$ (his worst possible payoff across beliefs). Hence, exclusivity allows the principal to construct a contract in which the agent is better off in state $\theta_{L}$ than in state $\theta_{H}$. This is also possible when exclusivity is not contractible if the principal sets a sufficiently high quantity in the contract. The problem in doing so, however, is that she distorts the agent's investment decision.

Now I turn to the question of equilibrium payoffs and investments.

Proposition 3. Suppose that quantity and exclusivity are contractible $(Q=E=[0,1])$. Then, in any equilibrium, investment levels are efficient (first-best in both states) and the 
principal always appropriates the first-best total surplus, i.e., the equilibrium payoff of the principal in state $\theta_{j}$ is $S\left(a_{j}^{0}, \theta_{j}\right)$ for all $j \in\{L, H\}$.

Proof. Consider an equilibrium and let $\widetilde{U}_{P}\left(\theta_{j}\right)$ denote the principal's payoff in state $\theta_{j}$ in that equilibrium. Lemma 5 implies that $\widetilde{U}_{P}\left(\theta_{j}\right) \geq S\left(a_{j}^{0}, \theta_{j}\right)$ for all $j \in\{L, H\}$. Individual rationality of the agent implies that it is not possible that $\widetilde{U}_{P}\left(\theta_{j}\right) \geq S\left(a_{j}^{0}, \theta_{j}\right)$ for all $j \in\{L, H\}$ and, simultaneously, $\widetilde{U}_{P}\left(\theta_{j}\right)>S\left(a_{j}^{0}, \theta_{j}\right)$ for some $j \in\{L, H\}$. The two preceding results imply that $\widetilde{U}_{P}\left(\theta_{j}\right)=S\left(a_{j}^{0}, \theta_{j}\right)$ for all $j \in\{L, H\}$. From individual rationality of the agent and the fact that $\widetilde{U}_{P}\left(\theta_{j}\right)=S\left(a_{j}^{0}, \theta_{j}\right)$ for all $j \in\{L, H\}$, it follows that investment must be efficient (first-best) in both states $\theta_{L}$ and $\theta_{H}$.

Proposition 3 establishes that in any equilibrium of the game when the principal can contractually use both quantity and exclusivity, the investment levels are efficient in both states $\theta_{L}$ and $\theta_{H}$. To illustrate why efficiency is always obtained when both quantity and exclusivity are contractible (as opposed to the case when only quantity is contractible), consider the derivation of the best separating allocation in Case 2 presented in the previous section (see Figure 3). Recall that, in that case, investment is inefficient due to the fact that the principal sets an excessively high quantity $\left(\bar{q}>q_{H}^{0}\right)$ in order to extract more surplus from the agent. When exclusivity is contractible, instead of increasing quantity above $q_{H}^{0}$, which induces the agent to overinvest in the relationship, the principal can set quantity $q_{H}^{0}$ and use (increase) exclusivity to move along the $\operatorname{IC}\left(\theta_{L}\right)$ constraint, signal her type and extract surplus from the agent. Surplus extraction can be achieved in this way because the direct surplus extraction effect associated with exclusivity is positive when the source of private information is the external. Moreover, exclusivity does not directly affect the agent's investment decision, implying that surplus extraction through exclusivity does not interfere with provision of investment incentives.

The preceding analysis shows that, in contrast with the case of private information about internal values (Section 3), contractibility of exclusivity has important implications when private information is about external values. In particular, it shows that the ability to contractually use exclusive provisions eliminates inefficient equilibria that may otherwise exist. I have therefore identified a situation in which contractibility of exclusivity enhances efficiency.

\section{Conclusion}

The literature on contractual solutions to the hold-up problem has focused on situations where the parties to the contract have symmetric information when contracting about future transactions. In this paper, I depart from this literature by examining a situation in which the party that designs the contract at the contracting phase has relevant private information. I show that because of information concerns, the contract designer may distort the contract's terms relative to those that induce efficient investment so as to signal information and appropriate more of the surplus generated. I also show that when private information concerns the 
value of trade with external parties, the ability to include exclusive clauses in the contract plays an important role in eliminating these distortions and, consequently, the inefficiency of investment.

Regarding the literature on the effect of exclusive contracts on relationship-specific investment, the analysis in this paper complements that in Segal and Whinston (2000) and De Meza and Selvaggi (2007). Following a cooperative approach to model renegotiation, Segal and Whinston (2000) show that renegotiable exclusivity contracts have no effect on relationship-specific investment. De Meza and Selvaggi (2007) point out that if the bargaining solution to renegotiation is non-cooperative, exclusivity may affect relationship-specific investments. The present paper contributes to this literature by providing a novel channel through which exclusive agreements affect relationship-specific investments. Concretely, because exclusivity signals information, it helps to mitigate the conflict between signalling information and providing incentives to invest that is present when parties contract under asymmetric information.

On a more practical level, this paper offers an explanation as to why contracts often specify simultaneously both a quantity to be traded in the future and an exclusivity clause. It also offers an explanation as to why firms voluntarily bind themselves by committing to trade exclusively with another firm. Furthermore, the effect of exclusivity that I highlight here may be important for policy design. The major (and unsettled) debate on that front is on whether exclusive agreements serve anticompetitive purposes and, as a consequence, on whether they should be contractually allowed. By showing that contractibility of exclusivity may enhance efficiency of investment, this paper suggests that a policy that systematically prohibits exclusive contacts may be misguided. 


\section{Appendix}

\section{A. Auxiliary Results}

Proposition 4. A best separating allocation $\widehat{m}=\left\{\widehat{c}_{L}, \widehat{c}_{H}\right\}$ is incentive compatible given the separating beliefs.

Proof. I only show here that given separating beliefs the principal of type $\theta_{H}$ prefers to choose $\widehat{c}_{H}$ instead of $\widehat{c}_{L}$. The proof that the principal of type $\theta_{L}$ prefers to choose $\widehat{c}_{L}$ instead of $\widehat{c}_{H}$ is perfectly analogous. Let $\left\{\widehat{c}_{L}, \bar{c}_{H}\right\}$ be a solution to the problem presented in (12) for the principal of type $\theta_{L}$. First, because $\left\{\widehat{c}_{L}, \bar{c}_{H}\right\}$ must satisfy the $\operatorname{IC}\left(\theta_{H}\right)$ constraint in the problem, we obtain that $U_{P}\left(\bar{c}_{H} ; a^{*}\left(\bar{c}_{H}, 1\right) \mid \theta_{H}\right) \geq U_{P}\left(\widehat{c}_{L} ; a^{*}\left(\widehat{c}_{L}, 0\right) \mid \theta_{H}\right)$. Second, because the constraints of the problem presented in (12) are exactly the same whether we are solving it for the principal of type $\theta_{L}$ or for the principal of type $\theta_{H},\left\{\widehat{c}_{L}, \bar{c}_{H}\right\}$ is also a feasible menu in the problem for the principal of type $\theta_{H}$. This immediately implies that $U_{P}\left(\widehat{c}_{H} ; a^{*}\left(\widehat{c}_{H}, 1\right) \mid \theta_{H}\right) \geq U_{P}\left(\bar{c}_{H} ; a^{*}\left(\bar{c}_{H}, 1\right) \mid \theta_{H}\right)$. From this inequality and the fact shown above that $U_{P}\left(\bar{c}_{H} ; a^{*}\left(\bar{c}_{H}, 1\right) \mid \theta_{H}\right) \geq U_{P}\left(\widehat{c}_{L} ; a^{*}\left(\widehat{c}_{L}, 0\right) \mid \theta_{H}\right)$, it follows that $U_{P}\left(\widehat{c}_{H} ; a^{*}\left(\widehat{c}_{H}, 1\right) \mid\right.$ $\left.\theta_{H}\right) \geq U_{P}\left(\widehat{c}_{L} ; a^{*}\left(\widehat{c}_{L}, 0\right) \mid \theta_{H}\right)$.

Lemma 6. Both when private information is about $v_{P}$ and when private information is about $V_{E}, U_{A}\left(t, q=1, e=0 ; a \mid \theta_{L}\right) \geq U_{A}\left(t, q=1, e=0 ; a \mid \theta_{H}\right)$ for all $t \in \mathbb{R}$ and all $a \in \mathcal{A}$.

Proof. By taking expectations of (1), we obtain that

$$
U_{A}(t, 1,0 ; a \mid \theta)=\frac{1}{2} \mathbb{E}\left[\max \left\{V(a), V_{E}\right\} \mid \theta\right]-\frac{1}{2} \mathbb{E}\left[v_{P}-v_{A}(a) \mid \theta\right]-\psi(a)-t .
$$

Because $\theta$ does not affect $v_{A}(a)$, we obtain that $U_{A}\left(t, q=1, e=0 ; a \mid \theta_{L}\right) \geq U_{A}(t, q=1, e=$ $\left.0 ; a \mid \theta_{H}\right)$ if and only if

$$
\mathbb{E}\left[\max \left\{V(a), V_{E}\right\}-v_{P} \mid \theta_{L}\right] \geq \mathbb{E}\left[\max \left\{V(a), V_{E}\right\}-v_{P} \mid \theta_{H}\right]
$$

When private information is about $v_{P},(14)$ follows directly from the fact that $\max \left\{V(a), V_{E}\right\}-$ $v_{P}$ is a decreasing function of $v_{P}$ and $F_{v_{P}}\left[. \mid \theta_{H}\right]$ first-order stochastically dominates $F_{v_{P}}[. \mid$ $\left.\theta_{L}\right]$. When private information is about $V_{E},(14)$ follows directly from the fact that $\max \left\{V(a), V_{E}\right\}-$ $v_{P}$ is an increasing function of $V_{E}$ and $F_{V_{E}}\left[\cdot \mid \theta_{L}\right]$ first-order stochastically dominates $F_{V_{E}}[\cdot \mid$ $\left.\theta_{H}\right]$.

Lemma 7. The proposed solution to Problem 2 (ignoring constraint $I C\left(\theta_{H}\right)$ ), i.e., contract $\widehat{c}_{H}=\left(\widehat{t}_{H}=U_{A}\left(0, q_{H}^{0} ; a^{*}\left(q_{H}^{0}, 1\right) \mid \theta_{H}\right), q_{H}^{0}\right)$ if Case 1 holds and contract $\widehat{c}_{H}=\left(\widehat{t}_{H}=\right.$ $\left.U_{A}\left(0, \bar{q} ; a^{*}(\bar{q}, 1) \mid \theta_{H}\right), \bar{q}\right)$ if Case 2 holds, satisfies constraint IC $\left(\theta_{H}\right)$ of Problem 2. 
Proof. I first prove the result for Case 1, i.e., that $U_{P}\left(\widehat{c}_{L} ; a^{*}\left(\widehat{c}_{L}, 0\right) \mid \theta_{H}\right) \leq U_{P}\left(\widehat{c}_{H} ; a^{*}\left(\widehat{c}_{H}, 1\right) \mid\right.$ $\left.\theta_{H}\right)$ when $\widehat{c}_{H}=\left(\widehat{t}_{H}, q_{H}^{0}\right)$ with $\widehat{t}_{H}=U_{A}\left(0, q_{H}^{0} ; a^{*}\left(q_{H}^{0}, 1\right) \mid \theta_{H}\right)$. Recall that contract $\widehat{c}_{L}=$ $\left(\widehat{t}_{L}, q_{L}^{0}\right)$ with $\widehat{t}_{L}=U_{A}\left(0, q_{L}^{0} ; a^{*}\left(q_{L}^{0}, 0\right) \mid \theta_{L}\right)$. The result is established by noting that

$$
\begin{aligned}
U_{P}\left(\widehat{c}_{L} ; a^{*}\left(\widehat{c}_{L}, 0\right) \mid \theta_{H}\right) & =U_{P}\left(0, q_{L}^{0} ; a^{*}\left(q_{L}^{0}, 0\right) \mid \theta_{H}\right)+U_{A}\left(0, q_{L}^{0} ; a^{*}\left(q_{L}^{0}, 0\right) \mid \theta_{L}\right) \\
& \leq U_{P}\left(0, q_{L}^{0} ; a^{*}\left(q_{L}^{0}, 0\right) \mid \theta_{H}\right)+U_{A}\left(0, q_{L}^{0} ; a^{*}\left(q_{L}^{0}, 0\right) \mid \theta_{H}\right) \\
& =S\left(a^{*}\left(q_{L}^{0}, 0\right), \theta_{H}\right) \\
& \leq S\left(a_{H}^{0}, \theta_{H}\right)=U_{P}\left(\widehat{c}_{H} ; a^{*}\left(\widehat{c}_{H}, 1\right) \mid \theta_{H}\right),
\end{aligned}
$$

where: $(i)$ the first equality follows from the fact that $U_{P}(t, q ; a \mid \theta)=U_{P}(0, q ; a \mid \theta)+t$ for all $q \in[0,1], a \in \mathcal{A}$ and $t \in R ;(i i)$ the first inequality follows from Condition 1; (iii) the second equality from (3); $(i v)$ the second inequality from the fact that $a_{H}^{0}$ is the investment level that maximizes $S\left(a, \theta_{H}\right)$; and $(v)$ the last equality from (3) again.

I now prove the result for Case 2, i.e., that $U_{P}\left(\widehat{c}_{L} ; a^{*}\left(\widehat{c}_{L}, 0\right) \mid \theta_{H}\right) \leq U_{P}\left(\widehat{c}_{H} ; a^{*}\left(\widehat{c}_{H}, 1\right) \mid\right.$ $\left.\theta_{H}\right)$ when $\widehat{c}_{H}=\left(\bar{q}, \widehat{t}_{H}\right)$ with $\widehat{t}_{H}=U_{A}\left(0, \bar{q} ; a^{*}(\bar{q}, 1) \mid \theta_{H}\right)$. I do this by comparing both $U_{P}\left(\widehat{c}_{H} ; a^{*}\left(\widehat{c}_{H}, 1\right) \mid \theta_{H}\right)$ and $U_{P}\left(\widehat{c}_{L} ; a^{*}\left(\widehat{c}_{L}, 0\right) \mid \theta_{H}\right)$ with $U_{P}\left(\widetilde{c}_{H} ; a^{*}\left(\widetilde{c}_{H}, 1\right) \mid \theta_{H}\right)$, where $\widetilde{c}_{H}=$ $\left(\widetilde{t}_{H}, q_{L}^{0}\right)$ with $\widetilde{t}_{H}$ such that $\widetilde{c}_{H}$ satisfies constraint $\operatorname{IC}\left(\theta_{L}\right)$ of Problem 2 with equality.

(1) Comparing $U_{P}\left(\widehat{c}_{H} ; a^{*}\left(\widehat{c}_{H}, 1\right) \mid \theta_{H}\right)$ with $U_{P}\left(\widetilde{c}_{H} ; a^{*}\left(\widetilde{c}_{H}, 1\right) \mid \theta_{H}\right)$. Because the expected payoff of the principal of type $\theta_{H}$ increases when moving along the $\operatorname{IC}\left(\theta_{L}\right)$ constraint by increasing quantity $q$ (see the derivation of the solution to Problem 2 in Section 4.3) and contract $\widehat{c}_{H}=\left(\bar{q}, \widehat{t}_{H}\right)$ (where $\left.\bar{q}>q_{L}^{0}\right)$ also satisfies constraint $\operatorname{IC}\left(\theta_{L}\right)$ with equality, we obtain that

$$
U_{P}\left(\widehat{c}_{H} ; a^{*}\left(\widehat{c}_{H}, 1\right) \mid \theta_{H}\right) \geq U_{P}\left(\widetilde{c}_{H} ; a^{*}\left(\widetilde{c}_{H}, 1\right) \mid \theta_{H}\right) .
$$

(2) Comparing $U_{P}\left(\widehat{c}_{L} ; a^{*}\left(\widehat{c}_{L}, 0\right) \mid \theta_{H}\right)$ with $U_{P}\left(\widetilde{c}_{H} ; a^{*}\left(\widetilde{c}_{H}, 1\right) \mid \theta_{H}\right)$. By construction, $\widetilde{c}_{H}$ satisfies constraint $\operatorname{IC}\left(\theta_{L}\right)$ with equality. Thus $U_{P}\left(\widetilde{c}_{H} ; a^{*}\left(\widetilde{c}_{H}, 1\right) \mid \theta_{L}\right)=U_{P}\left(\widehat{c}_{L} ; a^{*}\left(\widehat{c}_{L}, 0\right) \mid \theta_{L}\right)$, which is equivalent to

$$
\widehat{t}_{L}-\widetilde{t}_{H}=U_{P}\left(0, q_{L}^{0} ; a^{*}\left(q_{L}^{0}, 1\right) \mid \theta_{L}\right)-U_{P}\left(0, q_{L}^{0} ; a^{*}\left(q_{L}^{0}, 0\right) \mid \theta_{L}\right) .
$$

This means that $\widehat{t}_{L}-\widetilde{t}_{H}$ is identical to the incremental payoff to the principal of type $\theta_{L}$ associated with an increase in investment from $a^{*}\left(q_{L}^{0}, 0\right)$ to $a^{*}\left(q_{L}^{0}, 1\right)$. From Lemma 2 , it follows that

$$
\widehat{t}_{L}-\widetilde{t}_{H} \leq U_{P}\left(0, q_{L}^{0} ; a^{*}\left(q_{L}^{0}, 1\right) \mid \theta_{H}\right)-U_{P}\left(0, q_{L}^{0} ; a^{*}\left(q_{L}^{0}, 0\right) \mid \theta_{H}\right),
$$

which is equivalent to

$$
U_{P}\left(\widetilde{c}_{H} ; a^{*}\left(\widetilde{c}_{H}, 1\right) \mid \theta_{H}\right) \geq U_{P}\left(\widehat{c}_{L} ; a^{*}\left(\widehat{c}_{L}, 0\right) \mid \theta_{H}\right) .
$$

From (16) and (15) it follows that $U_{P}\left(\widehat{c}_{L} ; a^{*}\left(\widehat{c}_{L}, 0\right) \mid \theta_{H}\right) \leq U_{P}\left(\widehat{c}_{H} ; a^{*}\left(\widehat{c}_{H}, 1\right) \mid \theta_{H}\right)$.

Lemma 8. Suppose that $I C\left(\theta_{L}\right)$ is the binding constraint in Problem 2 when $q=q_{H}^{0}$ (Case 2). If a contract $c=(t, q)$ satisfies simultaneously $U_{P}\left(c ; a^{*}(c, 0) \mid \theta_{L}\right) \leq S\left(a_{L}^{0}, \theta_{L}\right)$ and $U_{P}\left(c ; a^{*}(c, 0) \mid \theta_{H}\right)>S\left(a^{*}(\bar{q}, 1), \theta_{H}\right)$ then $q>\bar{q}$. 
Proof. Given a contract $c=(t, q)$, conditions $U_{P}\left(c ; a^{*}(c, 0) \mid \theta_{L}\right) \leq S\left(a_{L}^{0}, \theta_{L}\right)$ and $U_{P}\left(c ; a^{*}(c, 0) \mid\right.$ $\left.\theta_{H}\right)>S\left(a^{*}(\bar{q}, 1), \theta_{H}\right)$ are equivalent to

$$
S\left(a^{*}(\bar{q}, 1), \theta_{H}\right)-U_{P}\left(0, q ; a^{*}(q, 0) \mid \theta_{H}\right)<t \leq S\left(a_{L}^{0}, \theta_{L}\right)-U_{P}\left(0, q ; a^{*}(q, 0) \mid \theta_{L}\right) .
$$

Therefore, they hold simultaneously only if in (17) the term on the right side of $t$ is greater than that on the left side. That is, only if

$$
S\left(a^{*}(\bar{q}, 1), \theta_{H}\right)-S\left(a_{L}^{0}, \theta_{L}\right)<U_{P}\left(0, q ; a^{*}(q, 0) \mid \theta_{H}\right)-U_{P}\left(0, q ; a^{*}(q, 0) \mid \theta_{L}\right) .
$$

Since by Lemma 2 the right-hand side of (18) is an increasing function of $q$, it suffices to show that condition (18) is not satisfied when $q=\bar{q}$. To obtain this, note that

$$
\begin{aligned}
S\left(a^{*}(\bar{q}, 1), \theta_{H}\right)-S\left(a_{L}^{0}, \theta_{L}\right) & =U_{P}\left(0, \bar{q} ; a^{*}(\bar{q}, 1) \mid \theta_{H}\right)-U_{P}\left(0, \bar{q} ; a^{*}(\bar{q}, 1) \mid \theta_{L}\right) \\
& \geq U_{P}\left(0, \bar{q} ; a^{*}(\bar{q}, 0) \mid \theta_{H}\right)-U_{P}\left(0, \bar{q} ; a^{*}(\bar{q}, 0) \mid \theta_{L}\right),
\end{aligned}
$$

where: $(i)$ the first equality is obtained by using the fact that $S\left(a^{*}(\bar{q}, 1), \theta_{H}\right)=U_{P}\left(0, \bar{q} ; a^{*}(\bar{q}, 1) \mid\right.$ $\left.\theta_{H}\right)+U_{A}\left(0, \bar{q} ; a^{*}(\bar{q}, 1) \mid \theta_{H}\right)$ and the fact the incentive compatibility of type $\theta_{L}$ is binding in the best separating allocation, i.e., $S\left(a_{L}^{0}, \theta_{L}\right)=U_{P}\left(0, \bar{q} ; a^{*}(\bar{q}, 1) \mid \theta_{L}\right)+U_{A}\left(0, \bar{q} ; a^{*}(\bar{q}, 1) \mid \theta_{H}\right)$; and (ii) the inequality follows from the fact that $U_{P}\left(0, \bar{q} ; a^{*}\left(\bar{q}, b_{H}\right) \mid \theta_{H}\right)-U_{P}\left(0, \bar{q} ; a^{*}\left(\bar{q}, b_{H}\right) \mid \theta_{L}\right)$ is an increasing function of $b_{H}$, which is an implication of Lemma 2. This completes the proof of the Lemma.

\section{B. Proofs of Propositions and Lemmas in the Main Text}

Proof. (of Proposition 1) Using the fact that investment and information affect only internal values, the expected payoffs of the principal and the agent, given contract $c=(t, q, e)$ and agent's beliefs $b_{H}$, can be written as:

$$
\begin{aligned}
U_{P}\left(c ; a^{*}\left(c, b_{H}\right) \mid \theta\right)= & \frac{1}{2} \mathbb{E}\left[\max \left\{V, V_{E}\right\}+q\left(v_{P}-v_{A}\right) \mid \theta, a^{*}\left(c, b_{H}\right)\right]+ \\
& +\frac{1}{2}(1-q)(1-e) \mathbb{E}\left[V_{E}\right]+t, \theta \in \Theta
\end{aligned}
$$

and

$$
\begin{aligned}
U_{A}\left(c ; a^{*}\left(c, b_{H}\right) \mid b_{H}\right)= & \left(1-b_{H}\right) \frac{1}{2} \mathbb{E}\left[\max \left\{V, V_{E}\right\}-q\left(v_{P}-v_{A}\right) \mid \theta_{L}, a^{*}\left(c, b_{H}\right)\right] \\
& +b_{H} \frac{1}{2} \mathbb{E}\left[\max \left\{V, V_{E}\right\}-q\left(v_{P}-v_{A}\right) \mid \theta_{H}, a^{*}\left(c, b_{H}\right)\right] \\
& -\frac{1}{2}(1-q)(1-e) \mathbb{E}\left[V_{E}\right]-\psi\left(a^{*}\left(c, b_{H}\right)\right)-t,
\end{aligned}
$$

where $a^{*}\left(c, b_{H}\right)$ is as defined in (4). Notice that the agent's payoff from investment is additively separable from both the exclusivity term $e$ and the transfer $t$. Thus, the agent's investment decision does not depend on $e$ and $t$, so instead of $a^{*}\left(c, b_{H}\right)$ we can simply write $a^{*}\left(q, b_{H}\right)$. From this observation and direct inspection of (19) and (20), we obtain that for the same beliefs $b_{H}$, contracts $c=(t, q, e)$ and $c^{\prime}(c)=\left(t^{\prime}, q^{\prime}, 0\right) \in C^{\prime}$ with $t^{\prime}=t-\frac{1}{2}(1-q) e \mathbb{E}\left[V_{E}\right]$ and $q^{\prime}=q$, generate the same expected payoffs to the principal (in both states $\theta_{L}$ and $\theta_{H}$ ) and agent, as well as the same agent's investment decision. 
I now show how to construct, for each equilibrium when the contract space is $C$, an outcome equivalent equilibrium when the contract space is $C^{\prime}$. Consider an equilibrium when the contract space is $C$. For each menu of contracts $m=\left\{c_{1}, \ldots, c_{n(m)}\right\}$ chosen with positive probability by the principal in this equilibrium, construct a corresponding menu $m^{\prime}(m)$ of contracts in $C^{\prime}$ in the following way: $m^{\prime}(m)=\left\{c^{\prime}\left(c_{1}\right), . ., c^{\prime}\left(c_{n(m)}\right)\right\}$. Let $M^{\prime}$ denote the set of menus constructed in this way. ${ }^{16}$ Now, consider the following strategies when the contract space is $C^{\prime}$. In each of the states in $\Theta$, the principal chooses menu $m^{\prime}(m) \in M^{\prime}$ with the same probability that she chooses menu $m$ in the equilibrium when the contract space is $C$. Moreover, in each of the states in $\Theta$, and for each menu $m^{\prime}(m) \in M^{\prime}$, the principal chooses contract $c^{\prime}\left(c_{j}\right) \in m^{\prime}(m)$ with the same probability that she chooses contract $c_{j} \in m$ in the equilibrium when the contract space is $C$. In a similar way, upon observing menu $m^{\prime}(m) \in M^{\prime}$ proposal and contract $c^{\prime}\left(c_{j}\right)$ choice by the principal, the agent's actions and beliefs are the same as after observing menu $m$ proposal and contract $c_{j}$ choice by the principal in the equilibrium when $C$ is the contract space. Menus $m \notin M^{\prime}$ are not chosen by the principal and therefore are off-the-equilibrium path. For all menus off-the-equilibrium path, let the actions of both the principal and the agent and the beliefs of the agent be the same as in the initial equilibrium when $C$ is the contract space. Since, contracts $c$ and $c^{\prime}(c)$ are outcome equivalent given the same beliefs and $C^{\prime} \subseteq C$, if the initial strategies constitute an equilibrium when $C$ is the contract space, then these strategies also constitute an equilibrium when $C^{\prime}$ is the contract space. Moreover, the two equilibria are outcome equivalent.

Proof. (of Lemma 3) I start by showing that there exists an allocation $\left\{c_{L}, c_{H}\right\}$, satisfying the constraints of problem (12), such that $U_{P}\left(c_{L} ; a^{*}\left(c_{L}, 0\right) \mid \theta_{L}\right)=S\left(a_{L}^{0}, \theta_{L}\right)$. Consider the allocation $\left\{\widehat{c}_{L}=\left(\widehat{t}_{L}, q_{L}^{0}\right), \bar{c}_{H}=\left(\bar{t}_{H}, q_{L}^{0}\right)\right\}$, where $\widehat{t}_{L}$ is such that $U_{A}\left(\widehat{c}_{L} ; a^{*}\left(q_{L}^{0}, 0\right) \mid \theta_{L}\right)=0$, i.e., $\operatorname{IR}\left(\theta_{L}\right)$ is satisfied with equality; and where $\bar{t}_{H}$ is such that

$$
U_{P}\left(\bar{c}_{H} ; a^{*}\left(q_{L}^{0}, 1\right) \mid \theta_{H}\right)=U_{P}\left(\widehat{c}_{L} ; a^{*}\left(q_{L}^{0}, 0\right) \mid \theta_{H}\right),
$$

i.e., $\mathrm{IC}\left(\theta_{H}\right)$ is satisfied with equality. By (3) (efficient ex-post renegotiation), the fact that $U_{A}\left(\widehat{c}_{L} ; a^{*}\left(q_{L}^{0}, 0\right) \mid \theta_{L}\right)=0$ implies that $U_{P}\left(\widehat{c}_{L} ; a^{*}\left(q_{L}^{0}, 0\right) \mid \theta_{L}\right)=S\left(a^{*}\left(q_{L}^{0}, 0\right), \theta_{L}\right)$, which is equal to $S\left(a_{L}^{0}, \theta_{L}\right)$ because $a^{*}\left(q_{L}^{0}, 0\right)=a_{L}^{0}$. Thus, $\left\{\widehat{c}_{L}, \bar{c}_{H}\right\}$ satisfies $\operatorname{IR}\left(\theta_{L}\right), \operatorname{IC}\left(\theta_{H}\right)$ and is such that $U_{P}\left(\widehat{c}_{L} ; a^{*}\left(\widehat{c}_{L}, 0\right) \mid \theta_{L}\right)=S\left(a_{L}^{0}, \theta_{L}\right)$. Hence, it remains only to show that $\left\{\widehat{c}_{L}, \bar{c}_{H}\right\}$ also satisfies constraints $\operatorname{IC}\left(\theta_{L}\right)$ and $\operatorname{IR}\left(\theta_{H}\right)$.

I first show that $\left\{\widehat{c}_{L}, \bar{c}_{H}\right\}$ satisfies constraint $\operatorname{IC}\left(\theta_{L}\right)$, i.e., that $U_{P}\left(\widehat{c}_{L} ; a^{*}\left(\widehat{c}_{L}, 0\right) \mid \theta_{L}\right) \geq$ $U_{P}\left(\bar{c}_{H} ; a^{*}\left(\bar{c}_{H}, 1\right) \mid \theta_{L}\right)$. Because $U_{P}(t, q ; a \mid \theta)=U_{P}(0, q ; a \mid \theta)+t$ for all $q \in[0,1], a \in \mathcal{A}$ and

\footnotetext{
${ }^{16}$ We implicitly consider that the specific placement of contracts within a menu distinguishes contracts that are otherwise identical, and that when constructing $M^{\prime}$ irrelevant contracts (e.g., contracts specifying a very low transfer such that they are never chosen by the principal) may be introduced in menus whenever necessary to differentiate between identical menus.
} 
$t \in R,(21)$ is equivalent to

$$
\widehat{t}_{L}-\bar{t}_{H}=U_{P}\left(0, q_{L}^{0} ; a^{*}\left(q_{L}^{0}, 1\right) \mid \theta_{H}\right)-U_{P}\left(0, q_{L}^{0} ; a^{*}\left(q_{L}^{0}, 0\right) \mid \theta_{H}\right) .
$$

Thus, $\widehat{t}_{L}-\widetilde{t}_{H}$ is identical to the incremental payoff to the principal of type $\theta_{H}$ associated with an increase in investment from $a^{*}\left(q_{L}^{0}, 0\right)$ to $a^{*}\left(q_{L}^{0}, 1\right)$. From Lemma 2, it follows that

$$
\widehat{t}_{L}-\bar{t}_{H} \geq U_{P}\left(0, q_{L}^{0} ; a^{*}\left(q_{L}^{0}, 1\right) \mid \theta_{L}\right)-U_{P}\left(0, q_{L}^{0} ; a^{*}\left(q_{L}^{0}, 0\right) \mid \theta_{L}\right),
$$

which is equivalent to $U_{P}\left(\widehat{c}_{L} ; a^{*}\left(\widehat{c}_{L}, 0\right) \mid \theta_{L}\right) \geq U_{P}\left(\bar{c}_{H} ; a^{*}\left(\bar{c}_{H}, 1\right) \mid \theta_{L}\right)$.

I now show that $\left\{\widehat{c}_{L}, \bar{c}_{H}\right\}$ satisfies constraint $\operatorname{IR}\left(\theta_{H}\right)$, i.e., that $U_{A}\left(\bar{c}_{H} ; a^{*}\left(\bar{c}_{H}, 1\right) \mid \theta_{H}\right) \geq 0$. Note that

$$
\begin{aligned}
U_{A}\left(\bar{c}_{H} ; a^{*}\left(\bar{c}_{H}, 1\right) \mid \theta_{H}\right)= & U_{A}\left(0, q_{L}^{0} ; a^{*}\left(q_{L}^{0}, 1\right) \mid \theta_{H}\right)-\bar{t}_{H} \\
= & \left\{U_{A}\left(0, q_{L}^{0} ; a^{*}\left(q_{L}^{0}, 1\right) \mid \theta_{H}\right)-U_{A}\left(0, q_{L}^{0} ; a^{*}\left(q_{L}^{0}, 0\right) \mid \theta_{L}\right)\right\} \\
& +\left[U_{P}\left(0, q_{L}^{0} ; a^{*}\left(q_{L}^{0}, 1\right) \mid \theta_{H}\right)-U_{P}\left(0, q_{L}^{0} ; a^{*}\left(q_{L}^{0}, 0\right) \mid \theta_{H}\right)\right],
\end{aligned}
$$

where: $(i)$ the first equality follows from the fact that $U_{A}(t, q ; a \mid \theta)=U_{A}(0, q ; a \mid \theta)-t$ for all $q \in[0,1], a \in \mathcal{A}$ and $t \in R$; and (ii) the second equality from (22) and the fact that $\widehat{t}_{L}=U_{A}\left(0, q_{L}^{0} ; a^{*}\left(q_{L}^{0}, 0\right) \mid \theta_{L}\right)$. Condition 1 implies that $U_{A}\left(0, q_{L}^{0} ; a^{*}\left(q_{L}^{0}, b_{H}\right) \mid \theta_{L}\right) \leq$ $U_{A}\left(0, q_{L}^{0} ; a^{*}\left(q_{L}^{0}, b_{H}\right) \mid \theta_{H}\right)$ for all $b_{H} \in[0,1]$, which in turn implies that $U_{A}\left(0, q_{L}^{0} ; a^{*}\left(q_{L}^{0}, b_{H}\right) \mid\right.$ $\left.b_{H}\right)$ is decreasing in $b_{H}$. Thus, the term in curly brackets in (23) is always positive. I next show that the term in square brackets is also positive. The derivative of $U_{P}\left(0, q_{L}^{0} ; a \mid \theta_{H}\right)$ with respect to $a$ is

$$
\frac{1}{2} v_{A}^{\prime}(a)\left[P_{s}\left(a, \theta_{H}\right)-q_{L}^{0}\right]
$$

The fact that, for all $a \in \mathcal{A}, P_{s}\left(a, \theta_{H}\right) \geq P_{s}\left(a, \theta_{L}\right)$ and $P_{s}\left(a, \theta_{L}\right)$ is increasing in $a$, implies that $P_{s}\left(a, \theta_{H}\right) \geq q_{L}^{0}$ for all $a \in\left[a^{*}\left(q_{L}^{0}, 0\right), a^{*}\left(q_{L}^{0}, 1\right)\right]$. (Recall that $q_{L}^{0} \equiv P_{s}\left(a^{*}\left(q_{L}^{0}, 0\right), \theta_{L}\right)$.) Since $v_{A}^{\prime}(a)>0$, this implies that $(24)$ is positive, meaning that $U_{P}\left(0, q_{L}^{0} ; a \mid \theta_{H}\right)$ is increasing in $a$. Thus, the term in square brackets in (23) is also positive and we obtain that $U_{A}\left(\bar{c}_{H} ; a^{*}\left(\bar{c}_{H}, 1\right) \mid\right.$ $\left.\theta_{H}\right)$. This completes the proof of existence of an allocation $\left\{c_{L}, c_{H}\right\}$, satisfying the constraints of problem (12), such that $U_{P}\left(c_{L} ; a^{*}\left(c_{L}, 0\right) \mid \theta_{L}\right)=S\left(a_{L}^{0}, \theta_{L}\right)$.

To see that the allocation proposed in this proof is in fact a solution to problem (12) for $j=L$, note that in any solution to problem (12) the payoff of the principal of type $\theta_{L}$ cannot exceed the first-best total surplus $S\left(a_{L}^{0}, \theta_{L}\right)$, otherwise constraint $\operatorname{IR}\left(\theta_{L}\right)$ would be violated. Finally, any menu $\left\{c_{L}, c_{H}\right\}$ solving problem (12) for $j=L$ must specify contract $c_{L}=\left(q_{L}^{0}, \widehat{t}_{L}\right)$, since the total surplus $S\left(a^{*}(q, 0), \theta_{L}\right)$ reaches its maximum value $S\left(a_{L}^{0}, \theta_{L}\right)$ at $q=q_{L}^{0}$. This completes the proof of the Lemma.

Proof. (of Lemma 4) When constraints $\operatorname{IC}\left(\theta_{L}\right)$ and $\operatorname{IR}\left(\theta_{H}\right)$ of Problem 2 hold with equality, they define continuous functions $t_{H}$ of $q_{H}$, which I denote by $t_{H}^{C}\left(q_{H}\right)$ and $t_{H}^{R}\left(q_{H}\right)$, respectively. Specifically,

$$
t_{H}^{C}\left(q_{H}\right)=S\left(a_{L}^{0}, \theta_{L}\right)-U_{P}\left(0, q_{H} ; a^{*}\left(q_{H}, 1\right) \mid \theta_{L}\right)
$$


and

$$
t_{H}^{R}\left(q_{H}\right)=U_{A}\left(0, q_{H} ; a^{*}\left(q_{H}, 1\right) \mid \theta_{H}\right)
$$

The remainder of the proof consists of two parts. I first show that $t_{H}^{C}\left(q_{H}\right)$ and $t_{H}^{R}\left(q_{H}\right)$ intersect each other in $\left[q_{H}^{0}, 1\right]$. I then show they intersect only once in that interval.

Part 1. Since $t_{H}^{C}\left(q_{H}\right)$ and $t_{H}^{R}\left(q_{H}\right)$ are continuous in $q_{H}$ and $t_{H}^{C}\left(q_{H}^{0}\right)<t_{H}^{R}\left(q_{H}^{0}\right)$ (Case 2), it is sufficient to show that $t_{H}^{C}(1) \geq t_{H}^{R}(1)$. By Lemma 6 (in Appendix A), $U_{A}\left(0,1 ; a^{*}(1,1) \mid\right.$ $\left.\theta_{L}\right) \geq U_{A}\left(0,1 ; a^{*}(1,1) \mid \theta_{H}\right)$, meaning that $t_{H}^{R}(1) \leq U_{A}\left(0,1 ; a^{*}(1,1) \mid \theta_{L}\right)$. Hence,

$$
t_{H}^{C}(1)-t_{H}^{R}(1) \geq S\left(a_{L}^{0}, \theta_{L}\right)-U_{P}\left(0,1 ; a^{*}(1,1) \mid \theta_{L}\right)-U_{A}\left(0,1 ; a^{*}(1,1) \mid \theta_{L}\right) .
$$

From (3), the right-hand side of (27) collapses into $S\left(a_{L}^{0}, \theta_{L}\right)-S\left(a^{*}(1,1), \theta_{L}\right)$, which is nonnegative since $a_{L}^{0}$ maximizes $S\left(a, \theta_{L}\right)$.

Part 2. I now show that $t_{H}^{C}\left(q_{H}\right)$ and $t_{H}^{R}\left(q_{H}\right)$ intersect once in $\left[q_{H}^{0}, 1\right]$ by showing that the difference $t_{H}^{C}\left(q_{H}\right)-t_{H}^{R}\left(q_{H}\right)$ is strictly increasing in $\left[q_{H}^{0}, 1\right]$. Substituting $U_{P}\left(0, q_{H} ; a^{*}\left(q_{H}, 1\right) \mid\right.$ $\left.\theta_{L}\right)$ and $U_{A}\left(0, q_{H} ; a^{*}\left(q_{H}, 1\right) \mid \theta_{H}\right)$ by their expressions obtained from taking expectations of (1) and (2), and noticing that $S\left(a^{*}\left(q_{H}, 1\right), \theta\right)=\mathbb{E}\left[\max \left\{V\left(a^{*}\left(q_{H}, 0\right), V_{E}\right)\right\} \mid \theta\right]-\psi\left(a^{*}\left(q_{H}, 0\right)\right)$ for all $\theta \in\left\{\theta_{L}, \theta_{H}\right\}$, we obtain that

$$
\begin{aligned}
t_{H}^{C}\left(q_{H}\right)-t_{H}^{R}\left(q_{H}\right)= & S\left(a_{L}^{0}, \theta_{L}\right)-\frac{1}{2}\left\{S\left(a^{*}\left(q_{H}, 1\right), \theta_{L}\right)+S\left(a^{*}\left(q_{H}, 1\right), \theta_{H}\right)\right\} \\
& +\frac{1}{2}\left\{\mathbb{E}\left[h\left(q_{H}, v_{P}, V_{E}\right) \mid \theta_{H}\right]-\mathbb{E}\left[h\left(q_{H}, v_{P}, V_{E}\right) \mid \theta_{L}\right]\right\},
\end{aligned}
$$

where $h\left(q_{H}, v_{P}, V_{E}\right)=q_{H}\left[v_{P}-v_{A}\left(a^{*}\left(q_{H}, 1\right)\right)\right]+\left(1-q_{H}\right) V_{E}$. Only the second and third terms in (28) depend on $q_{H}$. Consider first the second term. From the facts: $(i) a^{*}(q, 1)$ is an increasing function of $q$ (Lemma 1$),(i i) a^{*}(q, 1) \geq a_{j}^{0}$ for all $j \in\{L, H\}$ when $q \geq q_{H}^{0}$ and (iii) $S(a, \theta)$ is concave in investment $a$; it follows that both $S\left(a^{*}\left(q_{H}, 1\right), \theta_{L}\right)$ and $S\left(a^{*}\left(q_{H}, 1\right), \theta_{H}\right)$ are decreasing functions of $q_{H}$ when $q_{H} \geq q_{H}^{0}$. Consider now the third term in (28). When private information is about $v_{P}$ this term reduces to

$$
q_{H}\left(\mathbb{E}\left[v_{P} \mid \theta_{H}\right]-\mathbb{E}\left[v_{P} \mid \theta_{L}\right]\right] .
$$

This is an increasing function of $q_{H}$, since the fact that $F_{v_{P}}\left[. \mid \theta_{H}\right]$ strictly first-order stochastically dominates $F_{v_{P}}\left[. \mid \theta_{L}\right]$ implies that $\mathbb{E}\left[v_{P} \mid \theta_{H}\right]>\mathbb{E}\left[v_{P} \mid \theta_{L}\right]$. When private information is about $V_{E}$, the third term in (28) becomes

$$
\left(1-q_{H}\right)\left(\mathbb{E}\left[V_{E} \mid \theta_{H}\right]-\mathbb{E}\left[V_{E} \mid \theta_{L}\right]\right)
$$

This is also an increasing function of $q$, since the fact that $F_{V_{E}}\left[\cdot \mid \theta_{L}\right]$ strictly first-order stochastically dominates $F_{V_{E}}\left[. \mid \theta_{H}\right]$ implies that $\mathbb{E}\left[V_{E} \mid \theta_{H}\right]<\mathbb{E}\left[V_{E} \mid \theta_{L}\right]$. Therefore, both in the case of private information about $v_{P}$ and that of private information about $V_{E}, t_{H}^{C}\left(q_{H}\right)-$ $t_{H}^{R}\left(q_{H}\right)$ is increasing in $q_{H}$ when $q_{H} \in\left[q_{H}^{0}, 1\right]$. This completes the proof. 
Proof. (of Proposition 2) I start by introducing some additional notation. Let $b_{H}(m)$ denote the agent's belief that the principal is of type $\theta_{H}$ after observing that the principal proposed a menu $m \in M$. In a similar way, let $b_{H}(c, m)$ denote the agent's belief that the principal is of type $\theta_{H}$ after observing that the principal chose contract $c$ among those in $m$.

Before proceeding, note that the equilibrium concept adopted in this paper (Perfect Bayesian Equilibrium) does not impose any restriction on beliefs $b_{H}(m)$ off-the-equilibrium path. However, even off-the-equilibrium path, it requires two things. First, it requires that $b_{H}(c, m)$ be consistent with beliefs $b_{H}(m)$ and prescribed equilibrium play by the principal when choosing a contract from $m$ (consistency of beliefs). Second, it requires that the prescribed equilibrium play by the principal be optimal given beliefs $b_{H}(c, m)$; and that the prescribed agent's decision to accept or reject $m$ be optimal given beliefs $b_{H}(m)$ and the continuation equilibrium following the acceptance of $m$ (sequential rationality). Thus, any continuation equilibrium constructed in this proof must satisfy these requirements.

We are now in position to prove the result in the Proposition. Both types of principal proposing a menu $m \in M$, followed by a continuation equilibrium in which the payoff to the $\theta$-type principal $\widetilde{U}_{P}(\theta) \geq \widehat{U}_{P}(\theta)$ for all $\theta \in\left\{\theta_{L}, \theta_{H}\right\}$ constitutes an equilibrium of the overall game if exist off-the-equilibrium path beliefs and continuation equilibria such that no deviation to another menu is profitable. Since a deviation to a menu that is rejected by the agent is trivially not optimal to the principal, this proof consists of showing that if a menu $m^{\prime} \in M$ is such that for all beliefs $b_{H}\left(m^{\prime}\right)$ and all continuation equilibria the agent accepts it, then there are also beliefs $b_{H}\left(m^{\prime}\right)$ and a continuation equilibrium in which the payoff to the principals of type $\theta_{L}$ and of type $\theta_{H}$ are no larger than $\widehat{U}_{P}\left(\theta_{L}\right)$ and $\widehat{U}_{P}\left(\theta_{H}\right)$, respectively.

Let $m^{\prime} \in M$ be a menu that for all beliefs $b_{H}\left(m^{\prime}\right)$ and continuation equilibria following its proposal, the agent accepts it. Consider the following beliefs and continuation equilibrium following the proposal of $m^{\prime}: b_{H}\left(m^{\prime}\right)=0 ; b_{H}\left(c, m^{\prime}\right)=0$ for all $c \in m^{\prime}$; each type of principal chooses the contract in $m^{\prime}$ that maximizes her expected payoff given that $b_{H}\left(c, m^{\prime}\right)=0$. (Note that in this continuation equilibrium consistency of beliefs and sequential rationality by the principal are both satisfied.) Since $\widehat{U}_{P}\left(\theta_{L}\right)=S\left(a_{L}^{0}, \theta_{L}\right)$, menu $m^{\prime}$ must satisfy condition

$$
U_{P}\left(c ; a^{*}(c, 0) \mid \theta_{L}\right) \leq \widehat{U}_{P}\left(\theta_{L}\right) \text { for all } c \in m^{\prime}
$$

otherwise the payoff to the principal of type $\theta_{L}$ would be strictly larger than $S\left(a_{L}^{0}, \theta_{L}\right)$, which by (3) (efficient ex-post renegotiation) would imply a strictly negative expected payoff to the agent from accepting $m^{\prime}$. This would violate the assumption that $m^{\prime}$ is always accepted by the agent. Now, there are two possible cases regarding menu $m^{\prime}$ which I consider separately.

Case 1. Suppose that $m^{\prime}$ also satisfies $U_{P}\left(c ; a^{*}(c, 0) \mid \theta_{H}\right) \leq \widehat{U}_{P}\left(\theta_{H}\right)$ for all $c \in m^{\prime}$. Then, in the above continuation equilibrium the payoffs of both types of principal are no larger than those associated with the best separating allocation. As a consequence, the result that a continuation equilibrium in which the principal's payoffs are no larger than $\widehat{U}_{P}\left(\theta_{L}\right)$ and $\widehat{U}_{P}\left(\theta_{H}\right)$ exists, trivially holds. 
Case 2. Suppose that $m^{\prime}$ is such that $U_{P}\left(c ; a^{*}(c, 0) \mid \theta_{H}\right)>\widehat{U}_{P}\left(\theta_{H}\right)$ for some $c \in m^{\prime}$. The proof in this case is slightly more involved. Consider the (non-empty) set $C_{\theta_{H}}=\left\{c \in m^{\prime}\right.$ : $\left.U_{P}\left(c ; a^{*}(c, 0) \mid \theta_{H}\right)>\widehat{U}_{P}\left(\theta_{H}\right)\right\}$. I start by showing that

$$
U_{P}\left(c ; a^{*}(c, 1) \mid \theta_{H}\right) \leq \widehat{U}_{P}\left(\theta_{H}\right) \text { for all } c \in C_{\theta_{H}} .
$$

Suppose to the contrary that $U_{P}\left(c ; a^{*}(c, 1) \mid \theta_{H}\right)>\widehat{U}_{P}\left(\theta_{H}\right)$ for some $c \in C_{\theta_{H}}$. Consider in this case the following beliefs and continuation equilibrium: $b_{H}\left(m^{\prime}\right)=1 ; b_{H}\left(c, m^{\prime}\right)=1$ if $c \in C_{\theta_{H}}$ and $b_{H}\left(c, m^{\prime}\right)=0$ if $c \in m^{\prime} \backslash C_{\theta_{H}}$; each type of principal chooses the contract from $m^{\prime}$ that maximizes her payoff given beliefs $b_{H}\left(c, m^{\prime}\right)$. In this continuation equilibrium, the principal of type $\theta_{H}$ chooses a contract in $C_{\theta_{H}}$ and has payoff $\max _{c \in C_{\theta_{H}}} U_{P}\left(c ; a^{*}(c, 1) \mid \theta_{H}\right)>\widehat{U}_{P}\left(\theta_{H}\right)$. If $\widehat{U}_{P}\left(\theta_{H}\right)=S\left(a_{H}^{0}, \theta_{H}\right)$ (i.e., if Case 1 of the derivation of the best separating allocation holds), then by (3) (efficient ex-post renegotiation) the agent's expected payoff is negative. If $\widehat{U}_{P}\left(\theta_{H}\right)=S\left(a^{*}(\bar{q}, 1), \theta_{H}\right)$ (i.e., if Case 2 of the derivation of the best separating allocation holds), then by Lemma 8 all the contracts in $C_{\theta_{H}}$ specify a quantity $q>\bar{q}$ and so does the contract chosen by the principal of type $\theta_{H}$. From: $(i) S\left(a^{*}(q, 1), \theta_{H}\right)<S\left(a^{*}(\bar{q}, 1), \theta_{H}\right)$ for all $q>\bar{q}$, which stems from concavity of $S\left(a, \theta_{H}\right)$ in $a$; $(i i)$ the fact that $a^{*}\left(q_{H}^{0}, 1\right)$, which is smaller than $a^{*}(\bar{q}, 1)$, maximizes $\left.S\left(a, \theta_{H}\right)\right)$; and $(i i i)(3)$, which stems from efficient ex-post renegotiation; it follows that the agent's expected payoff must be negative. Thus, both when $\widehat{U}_{P}\left(\theta_{H}\right)=S\left(a_{H}^{0}, \theta_{H}\right)$ and when $\widehat{U}_{P}\left(\theta_{H}\right)=S\left(a^{*}(\bar{q}, 1), \theta_{H}\right)$, the agent's expected payoff is negative in this continuation equilibrium. This is a contradiction as $m^{\prime}$ is by assumption a menu that is accepted by the agent for all beliefs $b_{H}\left(m^{\prime}\right)$ and continuation equilibrium. This completes the proof that (30) holds.

I next use the fact that $m^{\prime}$ must satisfy conditions (29) and (30) to construct a continuation equilibrium in which the principal's payoffs are no larger than $\widehat{U}_{P}\left(\theta_{L}\right)$ and $\widehat{U}_{P}\left(\theta_{H}\right)$. Consider the following beliefs: for all $c \in m^{\prime} \backslash C_{\theta_{H}}$ let $b_{H}\left(c, m^{\prime}\right)=0$ while for all $c \in C_{\theta_{H}}$ let $b_{H}\left(c, m^{\prime}\right)$ be such that

$$
U_{P}\left(c ; a^{*}\left(c, b_{H}\left(c, m^{\prime}\right)\right) \mid \theta_{H}\right)=\widehat{U}_{P}\left(\theta_{H}\right) .
$$

Let us denote these beliefs by $\widetilde{b}_{H}\left(c, m^{\prime}\right)$. Note that they always exist, since $(i) U_{P}\left(c ; a^{*}(c, 1) \mid\right.$ $\left.\theta_{H}\right) \leq \widehat{U}_{P}\left(\theta_{H}\right)$ and $U_{P}\left(c ; a^{*}(c, 0) \mid \theta_{H}\right)>\widehat{U}_{P}\left(\theta_{H}\right)$ for all $c \in C_{\theta_{H}}$, and $(i i) U_{P}\left(c ; a^{*}\left(c, b_{H}\right) \mid\right.$ $\left.\theta_{H}\right)$ is continuous in $b_{H}$. Let $\widetilde{c}_{L}$ denote the best contract in $m^{\prime}$ for the principal of type $\theta_{L}$ given beliefs $\widetilde{b}_{H}(c, m)$.

Suppose first that $\widetilde{c}_{L} \notin C_{\theta_{H}}$. It is easy to see that beliefs $b_{H}\left(m^{\prime}\right)=0, b_{H}\left(c, m^{\prime}\right)=\widetilde{b}_{H}\left(c, m^{\prime}\right)$ for all $c \in m^{\prime}$, together with the principal of type $\theta_{L}$ choosing contract $\widetilde{c}_{L}$ and the principal of type $\theta_{H}$ choosing any contract in $C_{\theta_{H}}$ constitutes a continuation equilibrium following the proposal of $m^{\prime}$. Consistency of beliefs follows from the fact that we are free to choose beliefs $b_{H}\left(c, m^{\prime}\right)$ for all $c \neq \widetilde{c}_{L}$ in $m^{\prime}$, since $b_{H}\left(m^{\prime}\right)=0$. Sequential rationality follows from the following: given beliefs $\widetilde{b}_{H}\left(c, m^{\prime}\right)$, contract $\widetilde{c}_{L}$ is the best contract for the principal of type $\theta_{L}$ in $m^{\prime}$; and given beliefs $\widetilde{b}_{H}\left(c, m^{\prime}\right)$, the payoff of the principal of type $\theta_{H}$ is $\widehat{U}_{P}\left(\theta_{H}\right)$ if she chooses a contract in $c \in C_{\theta_{H}}$ and, by definition of $C_{\theta_{H}}$, a payoff smaller than $\widehat{U}_{P}\left(\theta_{H}\right)$ if she chooses a contract in $m^{\prime} \backslash C_{\theta_{H}}$. With these beliefs and continuation equilibrium, the 
agent accepts the menu proposal $m^{\prime}$ and the equilibrium payoff of the principal of type $\theta$ is no larger than $\widehat{U}_{P}(\theta)$, for all $\theta \in\left\{\theta_{L}, \theta_{H}\right\}$.

Suppose now that $\widetilde{c}_{L} \in C_{\theta_{H}}$. Consider, in this case, the following beliefs and continuation equilibrium: $b_{H}\left(m^{\prime}\right)=\widetilde{b}_{H}\left(\widetilde{c}_{L}, m^{\prime}\right) ; b_{H}\left(c, m^{\prime}\right)=\widetilde{b}_{H}\left(c, m^{\prime}\right)$ for all $c \in m^{\prime}$; both types of principal choose contract $\widetilde{c}_{L}$. Consistency of beliefs is trivially satisfied in this equilibrium. The justification of sequential rationality by the principal is the same as in the case in which $\widetilde{c}_{L} \notin C_{\theta_{H}}$. In this continuation equilibrium, both types of principal have lower payoffs than those associated with the best separating allocation: for the principal of type $\theta_{H}$ this is obvious; while for the principal of type $\theta_{L}$ the result follows from the fact that by condition (29) $U_{P}\left(\widetilde{c}_{L} ; a^{*}\left(\widetilde{c}_{L}, 0\right) \mid \theta_{L}\right) \leq \widehat{U}_{P}\left(\theta_{L}\right)$, the fact that the expected payoff of the principal of type $\theta_{H}$ decreases with an increase in investment from $a^{*}(c, 0)$ to $a^{*}\left(c, \widetilde{b}_{H}\left(c, m^{\prime}\right)\right)$ for all $c \in C_{\theta_{H}}$, and from Lemma 2. This completes the proof.

Proof. (of Lemma 5) This proof consists of showing that there exist contracts (one for each type of principal) that when proposed by the principal ensure her the efficient total surplus.

I begin with the principal of type $\theta_{L}$. Suppose that she proposes contract $c_{L}=\left(t_{L}, q_{L}^{0}, e=\right.$ $0)$, where $t_{L}=U_{A}\left(0, q_{L}^{0}, 0 ; a^{*}\left(q_{L}^{0}, 0\right) \mid \theta_{L}\right)$. The principal's payoff associated with proposing this contract depends both on the agent's decision to accept it and on the agent's investment decision after accepting it. Both of these decisions depend on the agent's beliefs about the principal's type. I first show that the agent accepts this contract regardless of his beliefs. By construction, $U_{A}\left(c_{L} ; a^{*}\left(c_{L}, b_{H}\right) \mid b_{H}\right)=0$ when $b_{H}=0$. Since contract $c_{L}$ specifies quantity $q_{L}^{0}$, it follows from Condition 1 that $U_{A}\left(c_{L} ; a^{*}\left(c_{L}, b_{H}\right) \mid b_{H}\right)$ is increasing in $b_{H}$. Thus, $U_{A}\left(c_{L} ; a^{*}\left(c_{L}, b_{H}\right) \mid b_{H}\right) \geq 0$ for all $b_{H} \in[0,1]$, meaning that the agent accepts the contract regardless of his beliefs. I next show that the payoff of the principal of type $\theta_{L}$ when the agent accepts contract $c_{L}$ is no less that $S\left(a_{L}^{0}, \theta_{L}\right)$ regardless of the agent's beliefs. The agent's belief $b_{H}$ affects the principal's payoff $U_{P}\left(c_{L} ; a^{*}\left(c_{L}, b_{H}\right) \mid \theta_{L}\right)$ only through its effect on the agent's investment decision. By construction of $c_{L}$ and the fact that $a^{*}\left(q_{L}^{0}, b_{H}=\right.$ $0)=a_{L}^{0}$, it follows that $U_{P}\left(c_{L} ; a^{*}\left(c_{L}, b_{H}\right) \mid \theta_{L}\right)=S\left(a_{L}^{0}, \theta_{L}\right)$ when $b_{H}=0$. Hence, to obtain that $U_{P}\left(c_{L} ; a^{*}\left(c_{L}, b_{H}\right) \mid \theta_{L}\right) \geq S\left(a_{L}^{0}, \theta_{L}\right)$ for all $b_{H} \in[0,1]$, it remains only to show that $U_{P}\left(c_{L} ; a^{*}\left(c_{L}, b_{H}\right) \mid \theta_{L}\right)$ is increasing in $b_{H}$. Using (8) and the chain rule to differentiate $U_{P}\left(c_{L} ; a^{*}\left(c_{L}, b_{H}\right) \mid \theta_{L}\right)$ with respect to $b_{H}$, we obtain

$$
\frac{1}{2} v_{A}^{\prime}\left(a^{*}\left(q_{L}^{0}, b_{H}\right)\right) \times\left[P_{s}\left(a^{*}\left(q_{L}^{0}, b_{H}\right), \theta_{L}\right)-q_{L}^{0}\right] \times \frac{\partial a^{*}\left(q_{L}^{0}, b_{H}\right)}{\partial b_{H}} .
$$

By assumption, $v_{A}^{\prime}(a)>0$ for all $a$. By Lemma $1, \partial a^{*}\left(q, b_{H}\right) / \partial b_{H} \geq 0$ for all $q$ and $b_{H}$. Since $P_{s}\left(a, \theta_{L}\right)$ is increasing in $a$ and $a^{*}\left(q, b_{H}\right)$ is increasing in $b_{H}, P_{s}\left(a^{*}\left(q_{L}^{0}, b_{H}\right), \theta_{L}\right) \geq$ $P_{s}\left(a^{*}\left(q_{L}^{0}, 0\right), \theta_{L}\right) \equiv q_{L}^{0}$ for all $b_{H} \in[0,1]$. From these three facts, it follows that (31) is positive for all $b_{H} \in[0,1]$, meaning that $U_{P}\left(c_{L} ; a^{*}\left(c_{L}, b_{H}\right) \mid \theta_{L}\right)$ is increasing in $b_{H}$.

Consider now the principal of type $\theta_{H}$. Suppose that she proposes contract $c_{H}=\left(t_{H}, q_{H}^{0}, e=\right.$ 1) where $t_{H}=U_{A}\left(0, q_{H}^{0}, 1 ; a^{*}\left(q_{H}^{0}, 1\right) \mid \theta_{H}\right)$. I proceed in the same way as I did in the case 
of the principal of type $\theta_{L}$. I start by proving that the agent accepts this contract regardless of his beliefs about the principal's type. By construction, $U_{A}\left(c_{H} ; a^{*}\left(c_{H}, b_{H}\right) \mid b_{H}\right)=0$ when $b_{H}=1$. I now show that $U_{A}\left(c_{H} ; a^{*}\left(c_{H}, b_{H}\right) \mid b_{H}\right)$ is decreasing in $b_{H}$. Differentiating $U_{A}\left(c_{H} ; a^{*}\left(c_{H}, b_{H}\right) \mid b_{H}\right)$ with respect to $b_{H}$, and noting that by the Envelope Theorem the effect of $b_{H}$ on $U_{A}\left(c_{H} ; a^{*}\left(c_{H}, b_{H}\right) \mid b_{H}\right)$ through its effect on investment is zero, we obtain

$$
U_{A}\left(c_{H} ; a^{*}\left(c_{H}, b_{H}\right) \mid \theta_{H}\right)-U_{A}\left(c_{H} ; a^{*}\left(c_{H}, b_{H}\right) \mid \theta_{L}\right) .
$$

From direct inspection of (5), the fact that $\theta$ affects only the external value $V_{E}$ and the fact that contract $c_{H}$ specifies $e=1,(32)$ reduces to

$$
\frac{1}{2} \mathbb{E}\left[\max \left\{V\left(a^{*}\left(c_{H}, b_{H}\right)\right), V_{E}\right\} \mid \theta_{H}\right]-\frac{1}{2} \mathbb{E}\left[\max \left\{V\left(a^{*}\left(c_{H}, b_{H}\right)\right), V_{E}\right\} \mid \theta_{L}\right] .
$$

Since the distribution of $V_{E}$ when the state is $\theta_{L}$ first-order stochastically dominates that when the state is $\theta_{H},(33)$ is negative. Thus $U_{A}\left(c_{H} ; a^{*}\left(c_{H}, b_{H}\right) \mid b_{H}\right)$ is decreasing in $b_{H}$. This, together with the fact shown above that $U_{A}\left(c_{H} ; a^{*}\left(c_{H}, b_{H}\right) \mid b_{H}\right)=0$ when $b_{H}=0$, implies that $U_{A}\left(c_{H} ; a^{*}\left(c_{H}, b_{H}\right) \mid b_{H}\right) \geq 0$ for all $b_{H} \in[0,1]$. Finally, I show that the payoff of the principal of type $\theta_{H}$ when the agent accepts contract $c_{H}$ is no less that $S\left(a_{H}^{0}, \theta_{H}\right)$ regardless of the agent's beliefs. By construction of $c_{H}$ and the fact that $a^{*}\left(q_{H}^{0}, b_{H}=1\right)=a_{H}^{0}$, it follows that $U_{P}\left(c_{H} ; a^{*}\left(c_{H}, b_{H}\right) \mid \theta_{H}\right)=S\left(a_{H}^{0}, \theta_{H}\right)$ when $b_{H}=1$. Furthermore, using (8) and the chain rule to differentiate $U_{P}\left(c_{H} ; a^{*}\left(c_{H}, b_{H}\right) \mid \theta_{H}\right)$ with respect to $b_{H}$, we obtain

$$
\frac{1}{2} v_{A}^{\prime}\left(a^{*}\left(q_{H}^{0}, b_{H}\right)\right) \times\left[P_{s}\left(a^{*}\left(q_{H}^{0}, b_{H}\right), \theta_{H}\right)-q_{H}^{0}\right] \times \frac{\partial a^{*}\left(q_{H}^{0}, b_{H}\right)}{\partial b_{H}} .
$$

Again, the first and last terms in (34) are positive. Because $P_{s}\left(a, \theta_{H}\right)$ is increasing in $a$ and $a^{*}\left(q_{H}^{0}, b_{H}\right)$ is increasing in $b_{H}, P_{s}\left(a^{*}\left(q_{H}^{0}, b_{H}\right), \theta_{H}\right) \leq P_{s}\left(a^{*}\left(q_{H}^{0}, 1\right), \theta_{H}\right) \equiv q_{H}^{0}$ for all $b_{H} \in$ $[0,1]$. Thus, the middle term in (34) is negative, implying that (34) is negative for all $b_{H} \in[0,1]$. This implies that $U_{P}\left(c_{H} ; a^{*}\left(c_{H}, b_{H}\right) \mid \theta_{H}\right) \geq U_{P}\left(c_{H} ; a^{*}\left(c_{H}, 1\right) \mid \theta_{H}\right)$ for all $b_{H} \in[0,1]$, which together with the fact that $U_{P}\left(c_{H} ; a^{*}\left(c_{H}, 1\right) \mid \theta_{H}\right)=S\left(a_{H}^{0}, \theta_{H}\right)$ implies that $U_{P}\left(c_{H} ; a^{*}\left(c_{H}, b_{H}\right) \mid \theta_{H}\right) \geq S\left(a_{H}^{0}, \theta_{H}\right)$ for all $b_{H} \in[0,1]$. 


\section{REFERENCES}

[1] AGHiOn, P. and BOLtON, P. "Contracts as a Barrier to Entry." American Economic Review, Vol. 77 (1987), pp. 388-401.

[2] AGHiOn, P., DEWATRIPONT, M. and REY, P. "Renegotiation Design with Unverifiable Information." Econometrica, Vol. 62 (1994), pp. 257-282.

[3] AGHiON, P. and HERMAlin, B. "Legal Restrictions on Private Contracts Can Enhance Efficiency." Journal Of Law Economics and Organization, Vol. 6 (1990), pp. 381-409.

[4] BEAUdRY, P. and POITEVIN, M. "Signalling and Renegotiation in Contractual Relationships." Econometrica, Vol. 61 (1993), pp. 745-782.

[5] CHE, Y.-K. and HAUSCH, D. B. "Cooperative Investments and the Value of Contracting." American Economic Review, Vol. 1 (1999), pp. 125-47.

[6] CHIU, S. "Noncooperative Bargaining, Hostages, and Optimal Asset Ownership." American Economic Review, Vol. 88 (1998), pp. 882-901.

[7] CHUNG, T.-Y. "Incomplete Contracts, Specific Investment, and Risk Sharing." Review of Economic Studies, Vol. 58 (1991), pp. 1031-1042.

[8] DE MEZA, D. and LOCKWOOD, B. "Does Asset Ownership Always Motivate Managers? Outside Options and the Property Rights Theory of the Firm." Quarterly Journal of Economics, Vol. 113 (1998), pp. 361-386.

[9] DE MEZA, D. and SELVAGGI, M. "Exclusive Contracts Foster Relationship-Specific Investment." Rand Journal of Economics, , Vol. 38 (2007), pp. 85-97.

[10] EDLIN, A. and REICHELSTEIN, S. "Holdups, Standard Breach Remedies, and Optimal Investment." American Economic Review, Vol 86 (1996b), pp. 478-501.

[11] FUDEnBERG, D. and TIROLE, J. Game Theory, Cambridge, Mass.: MIT Press, 1991.

[12] GROSSMAN, S. J. and HART, O. "The Costs and Benefits of Ownership: A Theory of Vertical and Lateral Integration." Journal of Political Economy, Vol. 94 (1986), pp. 691-719.

[13] HART, O. and MOORE, J. "Property Rights and the Nature of the Firm." Journal of Political Economy, Vol. 98 (1990), pp. 1119-1158.

[14] MACLEOD, W. B. and MALCOMSON, J. "Investments, Holdup, and the Form of Market Contracts." American Economic Review, Vol. 83 (1993), pp. 811-837.

[15] MASKIN, E. and TIROLE, J. "The Principal-Agent Relationship With an Informed Principal: The Case of Private Values." Econometrica, Vol. 58 (1990), pp. 379-409.

[16] MASKIN, E. and TIROLE, J. "The Principal-Agent Relationship With an Informed Principal, II: The Case of Common Values." Econometrica, Vol. 60 (1992), pp. 1-42.

[17] MASKIN, E. and TIROLE, J. "Two Remarks on the Property Rights Literature." Review of Economic Studies, Vol. 66 (1999), pp. 139-149.

[18] MYERSON, R. "Mechanism Design by an Informed Principal." Econometrica, Vol. 51 (1983), pp. 17671798.

[19] NOSAL, E. "Information Gathering by a Principal." International Economic Review, Vol. 47 (2006), pp. 1093-1111.

[20] ROGERSON, W. "Contractual Solutions to the Hold-Up Problem." Review of Economic Studies, Vol. 59 (1992), pp. 774-794.

[21] SEGAL, I. and WHINSTON, M. D. "Exclusive Contracts and Protection of Investments." Rand Journal of Economics, Vol. 31 (2000), pp. 3-33.

[22] SEGAL, I. and WHINSTON, M. D. "The Mirrlees Approach to Mechanism Design with Renegotiation (with Applications to Hold-up and Risk Sharing)." Econometrica, Vol. 70 (2002), pp. 1-46.

[23] SPIER, K. "Incomplete Contracts and Signalling." Rand Journal of Economics, Vol. 23 (1992), pp. 432443. 